\title{
MANF Is Essential for Neurite Extension and Neuronal Migration in the Developing Cortex
}

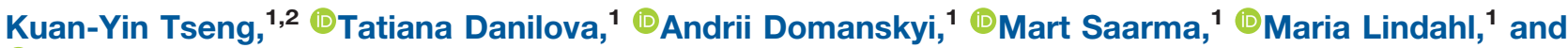 \\ (D) Mikko Airavaara ${ }^{1}$
}

DOI:http://dx.doi.org/10.1523/ENEURO.0214-17.2017

${ }^{1}$ Program in Developmental Biology, Institute of Biotechnology, University of Helsinki, Helsinki, 00014, Finland,

${ }^{2}$ Department of Neurological Surgery, Tri-Service General Hospital and National Defense Medical Center, Taipei, Taiwan

\section{Visual Abstract}

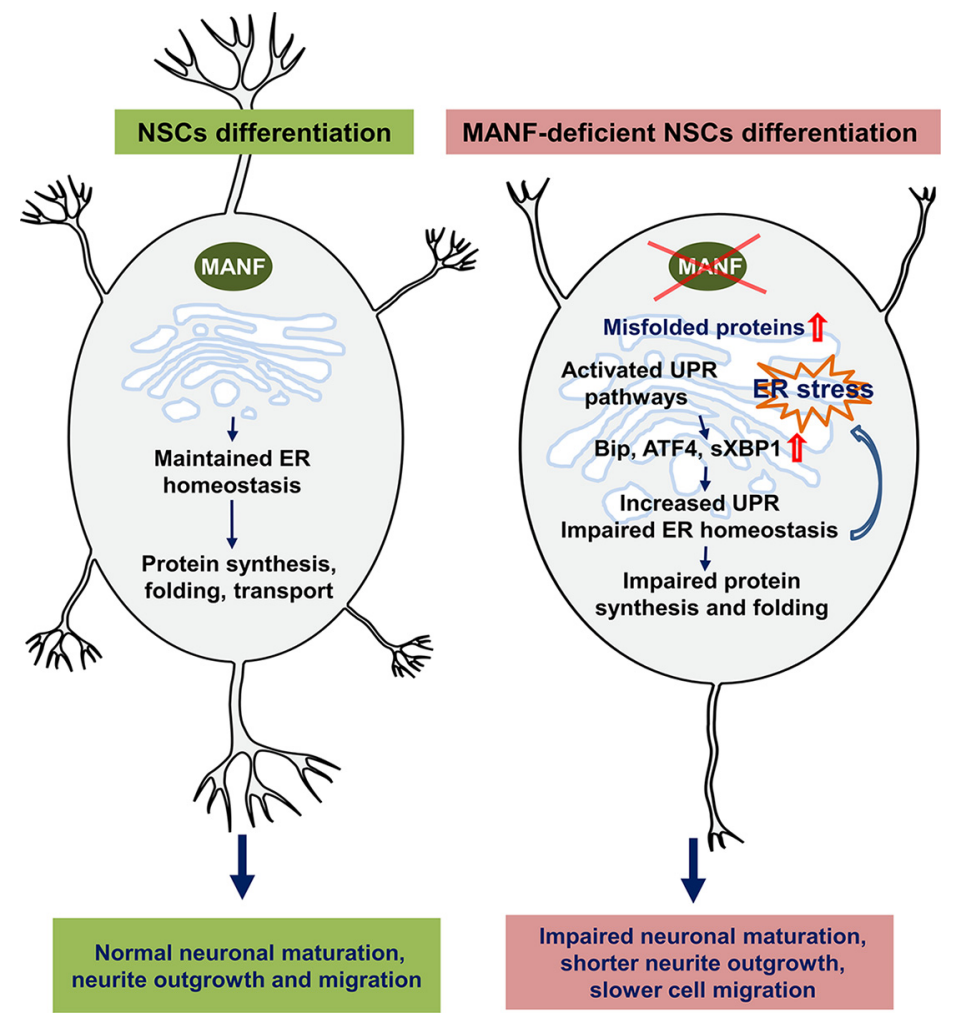

Mesencephalic astrocyte-derived neurotrophic factor (MANF) is an endoplasmic reticulum (ER) resident protein with neuroprotective effects. Previous studies have shown that MANF expression is altered in the developing rodent cortex in a spatiotemporal manner. However, the role of MANF in mammalian neurogenesis is not known. The aim of this study was to determine the role of MANF in neural stem cell (NSC) proliferation, differentiation, and cerebral cortex development. We found that MANF is highly expressed in neural lineage cells, including NSCs in the developing brain. We discovered that MANF-deficient NSCs in culture are viable and show no defect in proliferation. However, MANF-deficient cells have deficits in neurite extension upon neuronal differentiation. In vivo, MANF removal leads to slower neuronal migration and impaired neurite outgrowth. In vitro, mechanistic studies indicate that impaired neurite growth is preceded by reduced de novo protein synthesis and constitutively activated unfolded protein response (UPR) pathways. This study is the first to demonstrate that MANF is a novel and critical regulator of neurite growth and neuronal migration in mammalian cortical development.

Key words: cerebral dopamine neurotrophic factor; ER stress; MANF; neurotrophic factor; UPR

\section{Significance Statement}

Mesencephalic astrocyte-derived neurotrophic factor (MANF) is a neuroprotective protein, and its expression is high in the developing cortex. However, its role in mammalian neurogenesis is unknown. Here we show that MANF is highly expressed in neural lineage cells, including neural stem cells (NSCs) of the subventricular zone (SVZ) in the developing mouse brain. Unlike other neurotrophic factors, removal of MANF does not alter stem cell proliferation. However, removal of MANF disrupts neurite growth and migration of developing neurons into the cortex. Data in the current manuscript suggests that endogenous MANF is involved in neurite extension, as removal of MANF in NSCs leads to reduced de novo protein synthesis and activated unfolded protein response (UPR) on differentiation. 


\section{Introduction}

The neocortex is composed of various cell types having distinct morphology, position, pattern, and physiologic properties (Sato et al., 2012; Woodworth et al., 2012; Greig et al., 2013). Differentiation of neural stem cells (NSCs) or neural progenitor cells (NPCs) into distinct neuronal subtypes and their migration (Greig et al., 2013) require spatiotemporal activation of complex molecular cascades and proteostasis. Developmental studies in the mammalian neocortex have shown that intrinsic factors, including specific transcription factors, are necessary for cell type specification and differentiation (Grove and Fukuchi-Shimogori, 2003; Molyneaux et al., 2007; O'Leary and Sahara, 2008). The transcription factors Tbr1, CTIP2, and Cux1, expressed in different layers of the developing cortex, contribute to laminar fate determination (Alcamo et al., 2008; Chen et al., 2008; Cubelos et al., 2008; Bedogni et al., 2010). Moreover, extrinsic factors, such as glial cell line-derived neurotrophic factor and brain-derived neurotrophic factor, also regulate proliferation, cell type specification, differentiation, and migration of cortical neurons (Ferri and Levitt, 1995; McAllister et al., 1995; Canty et al., 2009). Previously, mesencephalic astrocyte-derived neurotrophic factor (MANF) and cerebral dopamine neurotrophic factor were identified as a new family of neurotrophic factors (Petrova et al., 2003; Lindholm et al., 2007) protecting dopamine neurons in animal models of Parkinson's disease (Voutilainen et al., 2009; Airavaara et al., 2012). We have shown that MANF is neuroprotective against cortical neurons in transient ischemic brain injury (Airavaara et al., 2009; Airavaara et al., 2010). Furthermore, we have recently shown that intracellular MANF protects primary neurons in vitro only when localized to the endoplasmic reticulum (ER; Hellman et al., 2011; Mätlik et al., 2015). In mouse brain, high Manf mRNA levels are detected in the cerebral cortex, hippocampus, and cerebellum (Lindholm et al., 2008). In rat brain, MANF is developmentally regu-

Received June 21, 2017; accepted September 5, 2017; First published September 11, 2017.

The authors declare no competing financial interests.

Author contributions: T.K.Y., A.D., M.S., M.L., and M.A. designed research; T.K.Y., T.D. performed research; T.D. contributed unpublished reagents/analytic tools; T.K.Y. and M.A. analyzed data; T.K.Y., A.D., M.L., M.S., and M.A. wrote the paper.

T.K.Y., A.D., M.A., and M.S. were supported by 3i-Regeneration by Tekes (Finnish Funding Agency for Innovation); M.A. and A.D. by Academy of Finland Grants 250275, 256398, 281394, 293392, and 309489; M.A. by the Sigrid Juselius Foundation, Instrumentarium Science Foundation; and M.S. by the Jane and Aatos Erkko Foundation and the Academy of Finland Grant 111926.

Acknowledgements: We want to thank Laura Lahti, Ph.D., and Congjun Zheng for establishing and helping with the NSC cultures and Maryna Koskela for the protein synthesis experiments. 3D-Histech whole slide scanning by HistoScanner service at the Institute of Biotechnology, University of Helsinki. We also thank Katrina Albert and Sandya Narayanswami for proofreading this manuscript.

Correspondence should be addressed to Dr. Mikko Airavaara, Program in Developmental Biology, Institute of Biotechnology, University of Helsinki, P.O. Box 56, 00014 Helsinki, Finland, E-mail: mikko.airavaara@helsinki.fi.

DOI:http://dx.doi.org/10.1523/ENEURO.0214-17.2017

Copyright (C) 2017 Tseng et al.

This is an open-access article distributed under the terms of the Creative Commons Attribution 4.0 International license, which permits unrestricted use, distribution and reproduction in any medium provided that the original work is properly attributed. lated in the cortex, where high levels are present in early postnatal days, and its expression declines as the cortex mature (Wang et al., 2014). These findings indicate that MANF is spatiotemporally expressed in the cortex and suggest that it may play a role in the maturation of cortical neurons. However, the brain phenotypes of MANF knockout mice and how deletion of MANF affects neurogenesis in the developing cerebral cortex have not been investigated.

In this study, we aimed to investigate the causal relationship between mammalian cortical neurogenesis and ER homeostasis during neuronal differentiation using MANF-deficient mice as a model system (Lindahl et al., 2014). These studies are necessary because mechanism of action for MANF is unsolved and its receptor(s) unknown. Furthermore, we used MANF-deficient mice to validate the specificity of MANF antibody to study MANF protein localization in the developing brain. We investigated the role of MANF in neurogenesis, neuronal differentiation, neurite growth and neuronal migration. In this report, we provide experimental evidence for a new functional role for MANF in the developing mammalian brain. Mechanistic in vitro studies show role of MANF in de novo protein synthesis and activation of unfolded protein response (UPR) during neuronal differentiation. Our results suggest that MANF is a crucial factor regulating ER homeostasis in neurons to support neurite growth and subsequent neuronal migration in the development of the cortex.

\section{Materials and Methods}

\section{Animals}

The generation of MANF knockout mice $\left(\mathrm{Manf}^{-/-}\right)$was as described previously (Lindahl et al., 2014). Briefly, $\mathrm{Manf}^{-/-}$mice are complete conventional knockout mice lacking MANF mRNA and protein in all tissues through efficient splicing of exon 2 to a reporter gene (Lindahl et al., 2014). The day of vaginal plug was designated as embryonic day (E)0.5. All experimental procedures were performed according to the $3 \mathrm{R}$ principles of the EU directive 2010/63/EU on the care and use of experimental animals, and local laws and regulations [Finnish Act on the Protection of Animals Used for Scientific or Educational Purposes (497/2013) and Government Decree on the Protection of Animals Used for Scientific or Educational Purposes (564/2013)].

\section{Isolation and cultivation of embryonic $\mathrm{Manf}^{-/-}$and Manf $^{+/+}$NSCs}

The telencephalons along with the lateral ventricle of E13.5 wild-type (WT) and Manf $^{-/-}$mice were isolated and triturated in Hanks' balanced salt solution (Invitrogen) by mild pipetting using 1-ml pipette tips. Dissociated cells were cultured in NSC growth medium containing DMEM/ F12 (Gibco) supplemented with B27 (20 $\mu \mathrm{l} / \mathrm{ml})$, epidermal growth factor (EGF; $20 \mathrm{ng} / \mathrm{ml}$ ), fibroblast growth factor-2 (FGF-2; 20 ng/ml; Gibco), GlutaMAX (10 $\mu \mathrm{l} / \mathrm{ml}$; Gibco), and penicillin-streptomycin $(50 \mathrm{U} / \mathrm{ml})$. The viable dissociated cells at a density of $5 \times 10^{5}$ cells $/ 10 \mathrm{ml}$ in NSC growth medium were seeded into uncoated T75 culture 
flasks at $37^{\circ} \mathrm{C}$ with $95 \%$ atmospheric air $/ 5 \% \mathrm{CO}_{2}$. Half of the medium was replaced every other day. After 5-7 d of culture, neurospheres were dissociated by trituration and digestion in Accutase solution (Gibco) for $10 \mathrm{~min}$ at $37^{\circ} \mathrm{C}$, cells were then centrifuged and resuspended in NSC growth medium. Neurospheres were passaged every 7-10 d. Viable NSC numbers were analyzed by staining with $0.5 \%$ trypan blue and counted in a cell counter (Bio-Rad). The primary passage of NSCs was not pure and contained a mixed cell population. After passage 10, cultured NSCs start to show signs of reduced viability and differentiation. We used NSCs from passages 3 to 10.

\section{Self-renewal assay}

To evaluate the self-renewal capacity of the cultured NSCs, we used a clonal colony-forming to measure the proportion of cells able to make neurospheres (Kerosuo et al., 2010). Single cell-dissociated cultures of NSCs were plated into 96-well plates with $10-15$ cells per well, and the number of formed neurospheres was counted after $7 \mathrm{~d}$. The number of neurospheres ( $>20$ cells tightly attached to each other) was divided by the number of initially plated cells giving the percentage of self-renewing cells.

\section{BrdU cell proliferation assay}

To measure proliferation, the percentage of NSCs in S-phase, NSCs were incubated with BrdU (1 mM, 5-bromo-2'-deoxyuridine; Sigma-Aldrich) for 12-16 h, centrifuged onto glass slides using a cytocentrifuge, fixed, and stained with anti-BrdU antibody. Slides were mounted with VectaShield mounting medium containing 4'-6-diamidino-2-phenylindole (DAPI; Vector Laboratories). A total of 12-18 images of each group was acquired using epifluorescence microscopy and analyzed by Image Pro Plus software (Media Cybernetics). The percentage of proliferating cells was estimated by dividing the number of BrdUpositive cells by the number of DAPI-stained nuclei.

\section{In vitro differentiation and apoptosis assays}

To induce differentiation, dissociated NSCs $\left(10^{5}\right.$ cells/ $\mathrm{ml}$ ) were plated onto cover glasses or four-well plates coated with $0.5 \mu \mathrm{g} / \mathrm{ml} \mathrm{laminin} / 10 \mu \mathrm{g} / \mathrm{ml}$ poly-L-ornithine and cultured in NSC growth medium for $1 \mathrm{~d}$. The next day, the medium was replaced with differentiation medium [penicillin-streptomycin (50 U/ml), B27 supplement (Gibco), 2 mM GlutaMAX (Gibco) in Neurobasal medium (Gibco)], and cells were allowed to differentiate for $7 \mathrm{~d}$ (see Figure $3 A$ ). Recombinant human MANF (rhMANF; $200 \mathrm{ng} / \mathrm{ml}$; Icosagen) was given in the Manf $^{-{ }^{-}}$cells at day in vitro (DIV)1. Differentiated cells were immunostained with celltype-specific antibodies followed by immunofluorescence microscopy. To estimate the number of apoptotic cells after NSC differentiation, cells $\left(10^{5}\right.$ cells $\left./ \mathrm{ml}\right)$ were fixed with $4 \%$ paraformaldehyde (PFA) and labeled for the deoxynucleotidyl transferase dUTP nick end labeling (TUNEL; Roche), according to the manufacturer's instructions. A near-infrared scanner was used to measure the intensity of the signal at $700 \mathrm{~nm}$ (Li-Cor Biosciences, Odyssey). Quantification was performed with Image Studio Software for the Odyssey. The signal of apoptotic cells was quantified from triplicate wells, and each experiment was repeated three to six times.

\section{Immunofluorescence staining}

NSCs grown on glass coverslips were fixed with $4 \%$ PFA for $15 \mathrm{~min}$ at room temperature (RT) and washed three times with PBS. Cells were blocked in blocking buffer (5\% bovine serum albumin, $0.3 \%$ Triton X-100 in PBS) for 1 $h$ at RT. Cells were then incubated with the following primary antibodies overnight at $4^{\circ} \mathrm{C}$ : rabbit anti-MANF $(1: 400$, Icosagen, catatog 310-100), mouse anti-Nestin (1:500; Millipore, catatog MAB353), goat anti-doublecortin (DCX; 1:200 Santa Cruz Biotechnology, catatog sc-8066), rabbit anti- $\beta$-tubulin III (Tuj1; 1:1000, BioLegend, catatog 802001), mouse antiGFAP (1:1000, Millipore, catalog MAB360), or rabbit antiMAP2 (1:500, Millipore, catatog AB5622). For fluorescence microscopy, appropriate secondary antibodies conjugated with Alexa Fluor 488 or 568, (1:500, Life Technologies) were used. Finally, coverslips were washed three times in PBS, stained with DAPI (Sigma-Aldrich) $5 \mu \mathrm{g} / \mathrm{ml}$ in PBS and mounted in fluorescent mounting medium (SHANDON, ThermoFisher Scientific). Fluorescence images were captured with Zeiss Axiolmager M2 482 epifluorescence microscope equipped with a 483 AxioCam $\mathrm{HRm}$ camera. Images were acquired with the AxioVision4 software. The percentages of DCX-, Tuj1-, MAP2-, and GFAP-positive cells were determined as the ratio of positive cell numbers to DAPI-stained nuclei from four different visual fields randomly selected on each coverslip. In vitro differentiation experiments were performed and analyzed in quadruplicate.

\section{Immunoblot analysis}

Cells were homogenized in NP-40 lysis buffer $(50 \mathrm{mM}$ Tris- $\mathrm{HCl}, \mathrm{pH} 7.4,0.15 \mathrm{M} \mathrm{NaCl}, 1.0 \mathrm{mM}$ EDTA, and $1 \%$ NP-40) freshly supplemented with phosphatase and protease inhibitor cocktail (Complete, Mini, EDTA-free, Roche Life Science), incubated on ice for 15-30 min and centrifuged at 13,000 rpm for $10 \mathrm{~min}$. Proteins were separated by $8 \%$ or $15 \%$ SDS-PAGE and transferred to nitrocellulose membranes. Immunoblot analysis using antibodies anti-Nestin (1:500, Millipore, catatog MAB353), anti-DCX (1:500, Santa Cruz Biotechnology, catatog sc8066), anti-TuJ1 (1:1000), anti-GFAP (1:1000, Millipore, catatog MAB360), anti-MAP2 (1:500, Millipore, catatog AB5622), anti-neurofilament (1:750, NF-200, Sigma-Aldrich, catatog N0142), anti-EIF2 $\alpha$ (1:1000, Cell Signal Technology, catatog 9721), anti-phospho (p)-EIF2 $\alpha$ (1:1000, Cell Signal Technology, catatog 9722S), anti- $\alpha$-tubulin (1:2000, LICOR, catatog 926-42213), and anti-GAPDH (1:2000, Millipore, catatog MAB374) was conducted. The membranes were washed twice for 10 min each in PBS containing $0.1 \%$ Tween (PBS-T) then probed with goat anti-mouse or goat anti-rabbit IR-Dye 670 or 800 secondary antibodies (LI-COR Biotechnology) in milk blocking buffer (5\%) with $0.1 \%$ Tween for $1 \mathrm{~h}$ at RT. After labeling with secondary antibodies, washes were repeated twice for 10 min with PBS-T, and then membranes were placed in water. Membranes were imaged using a LI-COR Odyssey scanner (LI-COR). 


\section{Analysis of neurite growth}

Images of 20-50 neurons from three microscope slides from each experiment were taken with a Zeiss Axiolmager M2 482 epifluorescence microscope. Representative cells with strong TUJ1 immunoreactivity in the neurite processes were analyzed. Neurites with lengths of at least twice the diameter of the cell body were measured. Neurite lengths from the soma were traced and measured using ImageJ software.

\section{RNA isolation, reverse transcription, and qPCR}

RNA from NSCs and differentiated cells at each time point were isolated using TriReagent (Molecular Research Center). cDNA from $2 \mu \mathrm{g}$ of total RNA was produced (RevertAid Premium Reverse Transcriptase, Thermo Fisher Scientific.; dNTP mix, ThermoFisher Scientific; oligo(dT) ${ }_{15}$ Primer, $500 \mu \mathrm{g} / \mathrm{ml}$, Promega). qPCR was performed using LightCycler 480 SYBR Green I Master mix (Roche Diagnostics $\mathrm{GmbH}$ ) and Roche LightCycler 480. Relative gene expression levels were normalized to $\beta$-actin in each sample. Primers used in qPCR for Grp78, Xbp1t, Xbp1s, Atf4, and Chop are published sequences (Lindahl et al., 2014).

\section{Histology and immunohistochemistry}

Whole mouse embryos or isolated brains from E13.5 to postnatal day (P)7 were fixed in $4 \%$ PFA at $4^{\circ} \mathrm{C}$ for at least $3 \mathrm{~d}$ and then embedded in paraffin and sectioned. Fivemicrometer coronal sections were cut from the cerebral plates (future cerebral cortex) along the anterior horn of the lateral ventricle from Manf $^{-/-}$mice and their WT littermates. Slides were deparaffinized and hydrated, then subjected to antigen retrieval in $10 \mathrm{mM}$ sodium citrate buffer, $\mathrm{pH} 6.0$, or $0.05 \%$ citraconic anhydride buffer, $\mathrm{pH}$ 7.4 , at $120^{\circ} \mathrm{C}$ for $10 \mathrm{~min}$. Immunohistochemistry was performed using the following antibodies: rabbit anti-MANF (1:1000, Icosagen, catatog 310-100), goat anti-DCX (1: 400, Santa Cruz Biotechnology, catatog sc-8066), rabbit anti-Tbr1 (Abcam, 1:500, catatog ab31940), rat anti-CTIP2 (1:400, Abcam, catatog ab18465), rabbit anti-CUX1 (Millipore, 1:100), rabbit anti-PAX6 (1:100, Abcam, catatog ab5790), rabbit anti-Tbr2 (1:500, Abcam, catatog ab75720), rabbit anti-phospho-histone $\mathrm{H} 3 \mathrm{(pH3} ; 1: 200$, Millipore, catatog 06-570), mouse anti-Nestin (1:400, Millipore, catatog MAB353), mouse anti-NeuN (1:400, Millipore, catatog MAB377), mouse anti-GFAP (1:500, Millipore, catalog MAB 360), mouse anti-NF-200 (1:1000, Sigma-Aldich, catatog N0142), rabbit anti-MAP2 (1:400, Millipore, catatog AB5622), rabbit anti-Reelin (1:300, Santa Cruz Biotechnology, catatog sc-5578), and rabbit anti-activated caspase III (1:200, Cell Signaling, catatog 9664$)$ at $4^{\circ} \mathrm{C}$ overnight. For fluorescence microscopy, appropriate secondary antibodies conjugated with Alexa Fluor 488 or 568 (1:500; Invitrogen) were used for visualization. For detection of a signal by light microscopy, biotinylated secondary antibody and peroxidase-conjugated streptavidin Vectastain ABC-detection system (Vector Laboratories) were used. Sections were developed with Vector diaminobenzidine peroxidase substrate kit (Vector Laboratories). Cortical layers were defined with cresyl violet staining.

\section{In vivo BrdU labeling and analysis}

For the cell division experiment, pregnant $\mathrm{Manf}^{+/-}$female mice (at E13.5 and E15.5) or their progeny (P1) were injected intraperitoneally with BrdU $(50 \mathrm{mg} / \mathrm{kg})$, which was dissolved in sterilized saline solution at a concentration of $10 \mathrm{mg} / \mathrm{ml}$. The injections were given three times with 3-h intervals, and brains were harvested 30 min after the last injection. For the birth-dating study, BrdU (100 mg/kg) was given in a single intraperitoneal injection to a pregnant mouse at E13.5 or E15.5, and embryos were dissected $4 \mathrm{~d}$ later (E17 or E19, respectively). The paraffin-embedded brain sections were dewaxed in xylene, rehydrated, processed for antigen retrieval with $10 \mathrm{mM}$ citrate buffer ( $\mathrm{pH}$ 6.0) and then immunostained with a mouse anti-BrdU (1:200, Abcam, catatog ab1893) overnight at $4^{\circ} \mathrm{C}$ followed by secondary antibodies conjugated to Alexa Fluor 488 (1:500; Invitrogen) for $2 \mathrm{~h}$ at RT. For S-phase progenitor cell quantification, the number of BrdU+ cells in the subventricular zone (SVZ) was counted at E13.5, E15.5, and P1 in each field under $10 \times$ magnification. For the birth-dating study of radial migration at E17, the distribution of BrdU-labeled cells was analyzed in the ventricular zone (VZ)/SVZ, intermediate zone (IZ), subplate (SP), and cortical plate (CP), respectively. At E19, to quantify the distribution of BrdUpositive nuclei, the $\mathrm{CP}$ from the pial side to ventricular side was divided into SVZ, IZ, cortical Layer V/VI, cortical Layer IV, and cortical Layer II/III.

\section{Homopropargylglycine (HPG) labeling and click chemistry}

For detecting and characterizing newly synthesized proteins during neuronal differentiation, we optimized the protocols for HPG incorporation and fluorescence detection. Dissociated NSCs $\left(10^{5} \mathrm{cell} / \mathrm{ml}\right)$ were plated onto 96-well plates coated with $0.5 \mu \mathrm{g} / \mathrm{ml}$ laminin $/ 10 \mu \mathrm{g} / \mathrm{ml}$ poly-L-ornithine and cultured in NSC growth medium for 1 d. The next day, the medium was replaced with differentiation medium. At times indicated, the medium was removed and replaced with L-methionine-free DMEM (Sigma-Aldrich) for $45 \mathrm{~min}$ to deplete methionine before the addition of HPG (Invitrogen) at a final concentration of $50 \mu \mathrm{M}$ for $1 \mathrm{~h}$ in L-methionine-free DMEM. The samples were fixed with $4 \%$ PFA for $15 \mathrm{~min}$ and subjected to Click-iT reaction cocktail, which contains $10 \mu \mathrm{M}$ Alexa Fluor 488-azide, $1 \mathrm{mM} \mathrm{CuSO}_{4}, 1 \times$ Click-iT HPG reaction buffer, and $1 \times$ Click-iT HPG buffer additive. The reaction was allowed to proceed for $40 \mathrm{~min}$ at RT in the dark. After removal of reaction cocktail, cells were washed in Click-iT reaction rinse buffer and then stained with DAPI. Fluorescence images were captured with Cellomics Celllnsight (Thermo Scientific) equipped with Olympus LUCPlanFL N $20 \times / 0.45$ objectives. Images were analyzed with the CellProfiler.

\section{Imaging and the analysis of imaging data}

For bright field imaging, a 3D-Histech (http://www. biocenter.helsinki.fi/bi/histoscanner/index.html) whole slide scanner was used. Image analysis was performed with Image-Pro Analyzer 7.0. Fluorescence or light microscopy images were captured with an Olympus BX61 light microscope equipped with a high-resolution color 
digital camera and Cell Life Science Microscopy software (Olympus Soft Imaging Solution) or using a Zeiss Axiolmager M2 482 epifluorescence microscope equipped with a 483 AxioCam HRm camera. Images were acquired with the AxioVision4 software. Cell-IQ was used to take the videos.

Cell counts in the dorsolateral neocortex were done as previously described (Fukumitsu et al., 2006). The cells were analyzed from an area of dorsomedial neocortical wall above the medial part of the lateral ventricle, which corresponds to the future primary somatosensory representation. Six to 12 coronal sections of the somatosensory cortex from three to six animals were analyzed. After immunofluorescent staining, cells were counted from images obtained by epifluorescence microscopy in a cortical sector ranging from the pial surface to lateral ventricle, $450 \times 350 \mu \mathrm{m}$ at E13.5 and E15.5; $1000 \times 600 \mu \mathrm{m}$ at E18.5, E19, and postnatal age. The number of mice at each time point was at least four per genotype. Four different brain sections per mouse were analyzed. For fluorescent intensity measuring, 8-bit grayscale images were taken at $10 \times$ magnification. Mean fluorescence values were measured in the CP at E19 or cerebral cortex at P7 and after background subtraction, the values for $\mathrm{Manf}^{-/-}$mice were normalized to those of age-matched WT controls.

\section{Statistical analysis}

All graphs and statistic calculations were performed in GraphPad Prism 6.0. A Student's $t$ test or ANOVA followed by Bonferroni correction test was conducted to test statistical significance. All data were tested for normality. All values and graphs in all figures are shown as mean \pm SEM. The results with $p<0.05$ were considered statistically significant.

\section{Results}

\section{Cell types expressing MANF in the developing mouse cortex}

MANF mRNA and protein are found in neurons in the developing and adult rodent brain (Lindholm et al., 2008; Wang et al., 2014). Cortical neurons express MANF in Layers II-VI in adult mouse brain and the neopallidal cortex in the E12.5 embryo (Lindholm et al., 2008). We analyzed the expression of MANF by immunohistochemistry during the development of the mouse cortex from E13.5 to P7. The specificity of MANF antibody was validated by comparing WT and $\mathrm{Manf}^{-/-}$cortical brain sections. MANF immunoreactivity was not observed in Manf $^{-/-}$mice with the antibodies used in this study (Fig. $1 A)$. We observed high levels of MANF immunoreactivity in the CP of the E13.5 and E15.5 mouse brain (Fig. 1B). At E18.5, when the laminated structure of the cerebral cortex develops, higher immunoreactivity of MANF was found in the middle layer of the $\mathrm{CP}$ (Fig. 1B, insets) compared to other layers. At P1, while MANF was expressed in all layers of the cortex, neurons at Layers IV/N of the cortex showed stronger MANF immunoreactivity (Fig. 1B, inset, arrow). Interestingly, MANF protein was preserved in cells in the neurogenic areas, VZ and SVZ, at all time points
A
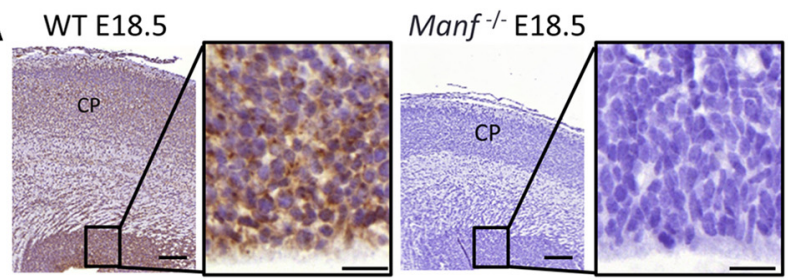

B

B $\quad \mathrm{E} 13.5$

E15.5
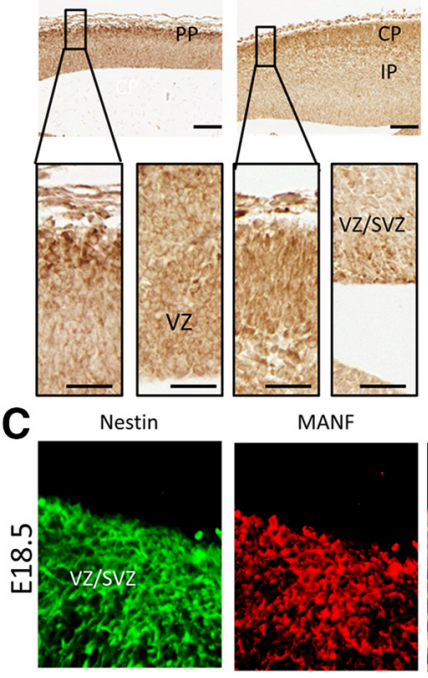

MANF
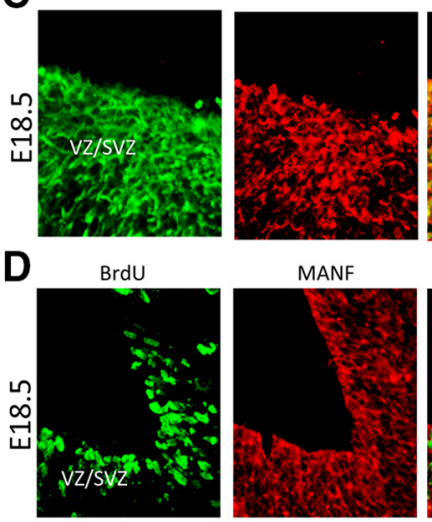

E18.5

P1

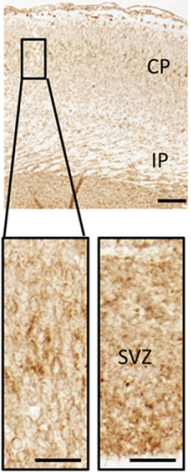

Merge
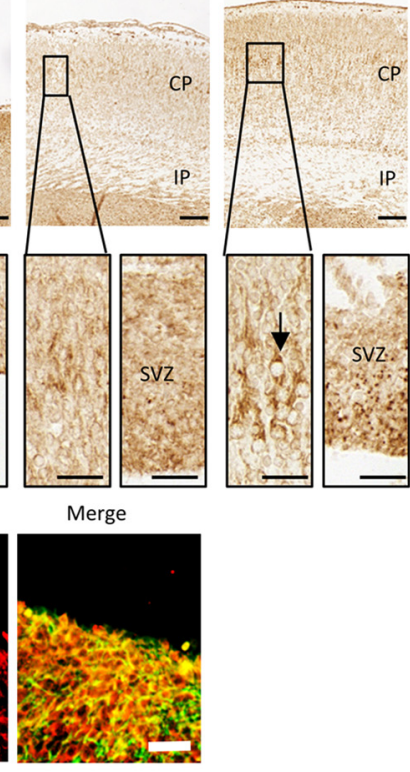

CP IP
E

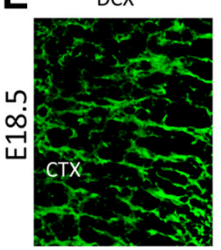

F

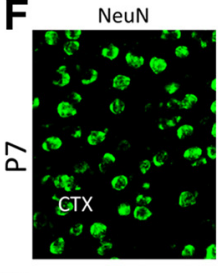

G
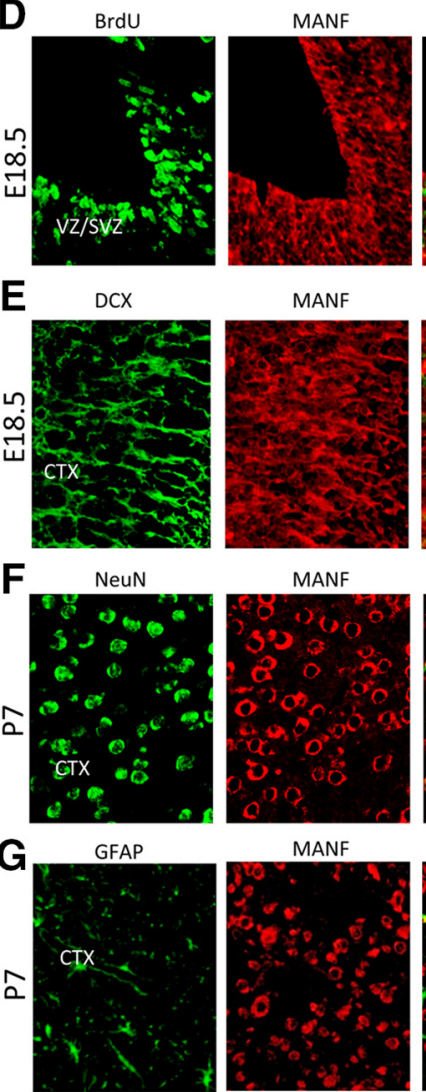

MANF

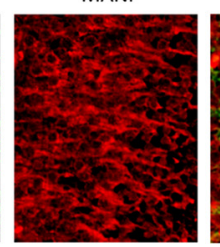

MANF

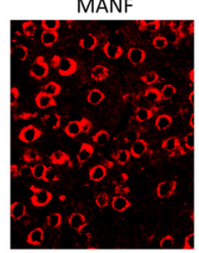

MANF
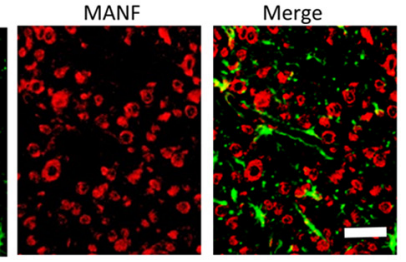

Figure 1. MANF expression in the developing cerebral cortex. A, Coronal cortical sections from E18.5 WT and Manf $^{-/-}$brains 


\section{continued}

stained with MANF antibody. The insets show photomicrographs of the VZ/SVZ in higher magnification. $\boldsymbol{B}$, In the E13.5 and E15.5 brain MANF is predominantly localized in cells of the PP/CP and modestly localized in the VZ/SVZ. By E18.5, strong MANF expression is seen in the VZ/SVZ and CP (inset). At P1, MANF is highly expressed in the VZ/SVZ and middle layers of the CP (inset). At E18.5, VZ/SVZ was double-stained for Nestin (green) and MANF (red) antibodies (C) and for BrdU (green) and MANF (red) antibodies $(\boldsymbol{D})$. $\boldsymbol{E}$, Section of cerebral cortex from E18.5 mice double-stained with DCX (green) and MANF (red) antibodies. $\boldsymbol{F}$, Section of cerebral cortex from P7 mice double-stained with NeuN (green) and MANF (red) antibodies. G, Section of cerebral cortex from P7 mice double-stained with GFAP (green) and MANF (red) antibodies; scale bars: $100 \mu \mathrm{m}(\boldsymbol{A}, \boldsymbol{B}), 20 \mu \mathrm{m}(\boldsymbol{A}$, $\boldsymbol{B}$ inset), $50 \mu \mathrm{m}(\boldsymbol{C}-\mathbf{G})$. PP, preplate; CP, cerebral plate; IP, intermediate plate.

(Fig. 1B). To identify cells expressing MANF in the developing brain, we used double immunofluorescent staining with antibodies against Nestin and DCX, which are widely used markers for NSCs and NPCs, respectively. BrdU was used to label S-phase progenitor cells. MANF was colocalized with Nestin (Fig. 1C) and MANF was found in BrdU-positive cells (Fig. 1D) in VZ/SVZ of E18.5 brain. Also, MANF was found in DCX-positive cells at E18.5 (Fig. $1 E$ ) and in NeuN-positive cells, but not in GFAP-positive cells at P7 (Fig. 1F,G) in mouse cortex. These results demonstrated that MANF is not only expressed in postmitotic neurons but also in mitotic NSCs in the developing brain. High expression levels of MANF in the CP and VZ/SVZ during embryonic development suggests that MANF may have multiple functions during cortical development.

\section{Lack of MANF does not affect NSC proliferation, self-renewal, or viability}

Next, we studied the role of MANF in NSCs by establishing NSC cultures from E13.5 mouse brains. NSCs are multipotent and self-renewing to form neurospheres in culture. We found that most of the WT NSCs expressed MANF protein whereas Manf $^{-{ }^{-}}$NSCs were negative for MANF immunofluorescence (Fig. 2A). Using a self-renewal assay, where neurospheres are dissociated into single cells and their ability to form new neurospheres is measured, no difference was found between the two genotypes (Fig. 2B). Next, we studied whether MANF deletion affects the heterogeneous population of NSCs and stained WT and Manf $^{-{ }^{--}}$cells with the NSC marker Nestin, and the NPC marker DCX. There was no difference in the numbers of Nestin-positive or DCX-positive cells between the two genotypes (Fig. 2C-F). Also, Western blot analysis showed no difference between the genotypes of Nestin, GFAP, or DCX levels measured from neurospheres (Fig. 2G,H). Next, we measured whether MANF deletion affects the viability of NSCs and found that the number of trypan blue-stained dead cells was similar between the genotypes (Fig. 2/). The proliferation rate of cells, as expressed by the ratio of BrdU+ cells to the total cell number was also similar between the two groups (Fig. $2 J, K)$. In short, MANF deficiency did not affect self- renewal capacity, viability, proliferation, or Nestin, DCX, and GFAP levels in cultured NSCs.

\section{Loss of MANF interferes with neuronal differentiation and impairs neurite outgrowth}

To investigate whether MANF is involved in neuronal differentiation and neurite growth in vitro, NSCs were allowed to differentiate in medium without mitogens (EGF, FGF-2) for $8 \mathrm{~d}$ (Fig. 3A). Initially, the changes in morphology of differentiated neurons from DIV1 to DIV4 (Video 1 , WT; Video 2, $\mathrm{Manf}^{-/}$) were studied and cells were stained with a TuJ1 antibody, a marker for postmitotic immature neurons (Fig. 3B). At DIV1, the WT and Manf $^{-/-}$cells displayed slightly asymmetrical morphology. At DIV2, WT cells showed clear neurite outgrowth and increased neurite extensions at DIV4. Contrarily, Manf $^{-/-}$cells did not show neurite outgrowth at DIV2, and at DIV4 neurite length was decreased compared to WT (Fig. 3B,C), indicating that loss of MANF disrupts neurite outgrowth. Therefore, we investigated whether decreased neurite outgrowth, caused by loss of MANF, can be improved by administration of rhMANF $(200 \mathrm{ng} / \mathrm{ml})$. Indeed, a single application of rhMANF could induce neurite outgrowth in Manf $^{-/-}$cells at DIV2, but did not continue to promote the neurite extension at DIV4 (Fig. 3B,C), suggesting that extracellular MANF did not completely recover a deficit of neurite outgrowth from loss of endogenous MANF. At DIV8, we found that the number of DCX-positive cells was similar between the genotypes, but there were fewer TuJ1- and MAP2-positive cells in Manf ${ }^{-/-}$group compared to WT group (Fig. $3 D-F, p<0.01$, Student's $t$ test). The number and morphology of GFAP-positive cells did not differ between the two groups (Fig. 3E,F), implying that loss of MANF only disrupts the neuronal differentiation in vitro. In addition, at DIV8 analysis of total neurite length revealed that Tuj1-positive Manf $^{-/-}$cells displayed significantly shorter neurites compared to WT neurons (Fig. $3 G, H)$. In line with the immunocytochemical staining, Western blotting revealed decreased levels of TuJ1 and MAP2, but not DCX or GFAP, in the $\mathrm{Manf}^{-/-}$group (Fig. $3 /, J, p<0.05, p<0.01$, respectively, Student's $t$ test). These results indicate that MANF plays a significant role in neuronal differentiation and neurite outgrowth.

\section{Altered thickness of the cerebral cortex in $\mathrm{Manf}^{-/-}$ mice}

Given the observed effect of MANF knockout on neuronal differentiation in vitro, we investigated whether deletion of MANF affects the development of neocortex. We measured the thickness of WT and Manf ${ }^{-1-}$ cortical structures after Nissl-staining during embryonic and postnatal corticogenesis. At E13.5, the histologic appearance of the cerebral wall in mutants and their WT littermates was similar (Fig. 4A,B). At E15.5, IZ and CP of the neocortex was thinner in Manf $^{-/}$embryos than in WT littermates (Fig. $4 C, D, N, O)$. At E18.5, the CP was thinner in the Manf ${ }^{-/}$ group, and the thickness of $\mathrm{IZ}$ was similar between the genotypes (Fig. $4 E, F, N, O$ ). However, cell densities in the $I Z$ and $C P$ of the mutant brain were higher (Fig. $4 K, Q$ ). At $\mathrm{P} 1$ and $\mathrm{P} 7$, the thickness of the $\mathrm{Manf}^{-{ }_{-}}$cerebral cortex was reduced, particularly the Layers II-IV and V, com- 
A

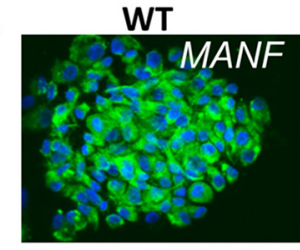

C

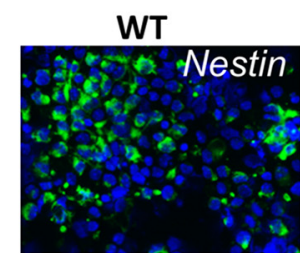

E
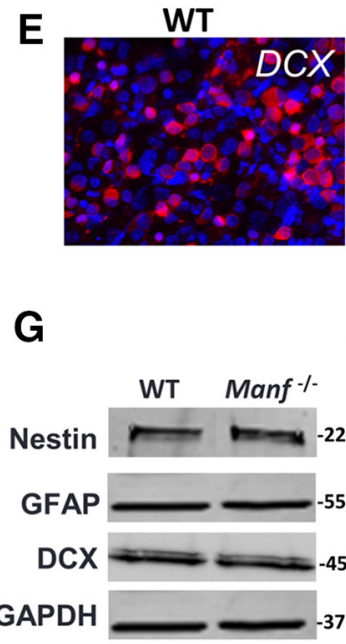

J

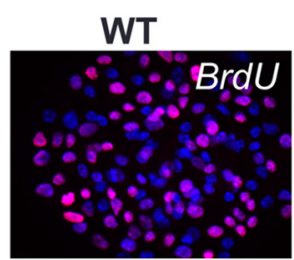

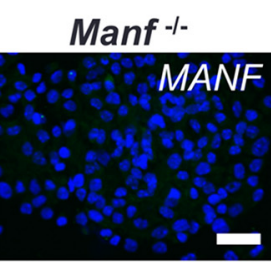

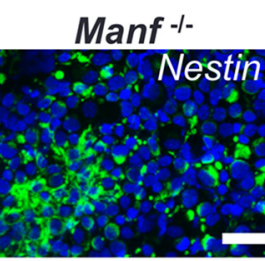

Manf ${ }^{-1}$

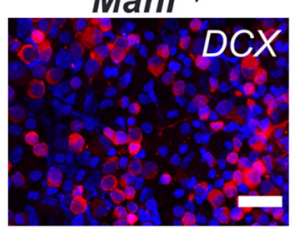

H

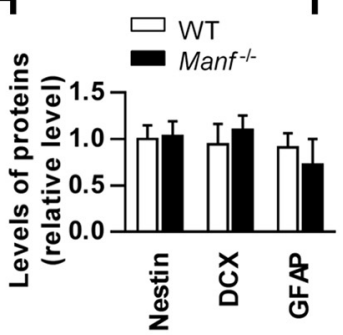

B

D

$F$
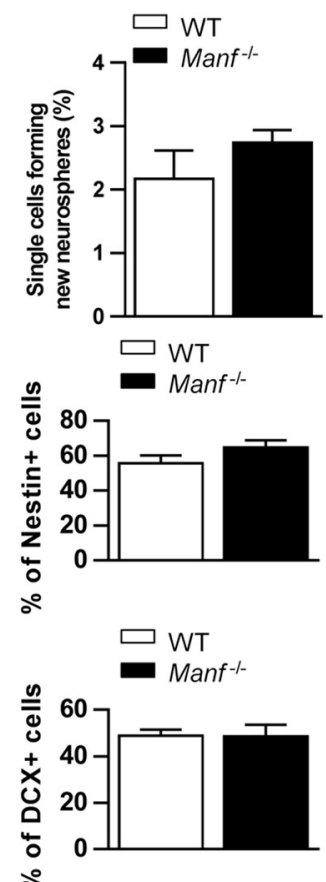

¿

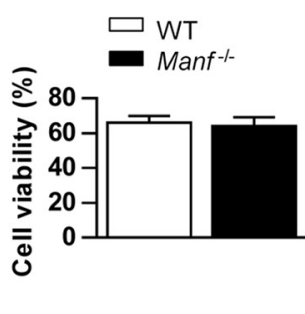

Figure 2. In vitro characterization of cultivated WT and Manf ${ }^{-/-}$NSCs. A, Immunofluorescent staining with MANF (green) antibody shows high expression in WT neurospheres, and no signal in $\mathrm{Manf}^{-/-}$neurospheres. $\boldsymbol{B}$, There was no difference in the self-renewal assay in NSCs of Manf $^{-/-}$and WT groups $(p=0.25, n=4)$. Immunofluorescent staining with Nestin (green, C), DCX (red, $\boldsymbol{E}$ ) antibodies and counterstained with DAPI (blue) in WT and Manf ${ }^{-/-}$NSCs. The percentage of Nestin-positive NSCs (D) and DCX-positive (F) neuronal precursor cells in WT and Manf $^{-/-}$NSC cultures were analyzed by counting the ratio of Nestin- or DCX-positive cells to DAPI-positive nuclei, $n=3-5$. NSCs were analyzed by Western blotting for Nestin, DCX, GFAP in WT and Manf ${ }^{-/-}$NSCs (G). Quantitative data from Western blottings $(\boldsymbol{H})$ are presented as levels relative to GAPDH, $n=3-5$. Numbers on the right show molecular weight as kDa. Cell viability did not differ between WT and Manf ${ }^{-/-}$NSCs (I). $\boldsymbol{J}, \boldsymbol{K}$, NSC proliferation assessed from BrdU-positive cells (red) as a ratio from DAPI-positive nuclei (blue) from NSC cultures, $n=5-6$; scale bar: $50 \mu \mathrm{m}$.

pared to the same area in WT cortex (Fig. 4G-J,N). Additionally, the corresponding higher cell density in Layer II-IV was observed in the mutant cortex at P7 (Fig. 4L,Q). In contrast, Layer VI was of normal size. The results indicate that loss of MANF in vivo does not affect the size of the VZ/SVZ but causes abnormal cerebral cortex development.

To determine if impaired $\mathrm{Manf}^{-/-}$neocortical development is caused by a decreased rate of proliferation in NSCs, we injected pregnant heterozygous $\mathrm{Manf}^{+/-}$mice or $\mathrm{P} 1$ pups with BrdU and harvested brain tissues 30 min later. BrdU immunofluorescence was performed on brain sections from $\mathrm{E} 13.5,15.5$, and $\mathrm{P} 1$ animals to analyze cells in S-phase (DNA synthesis). $\mathrm{pH} 3$ immunofluorescence was conducted at E15.5 to analyze cells in M-phase (mitosis). The number of cells in S- or M-phase quantified from coronal sections was similar in the Manf $^{-/}$cortex compared to WT littermates (Fig. 5A-D). Additionally, quantification of the number of neuroepithelial cells, and intermediate progenitor cells, stained with PAX6 and 
A

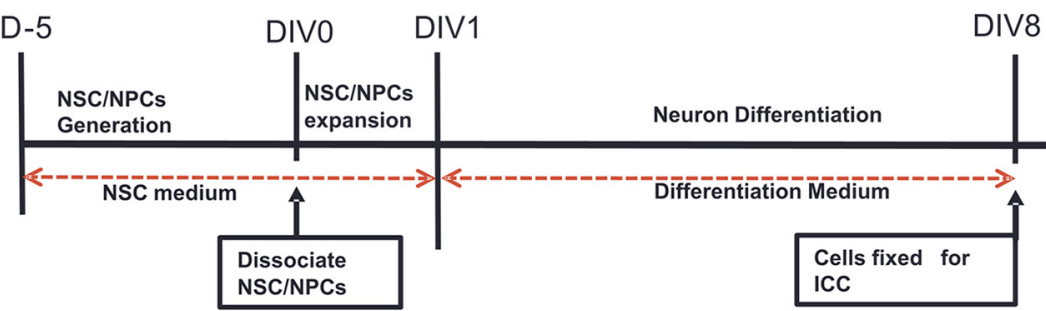

B

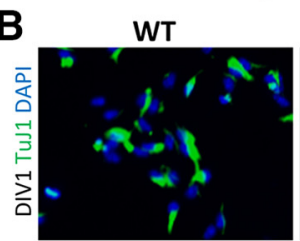

Manf ${ }^{-/-}$
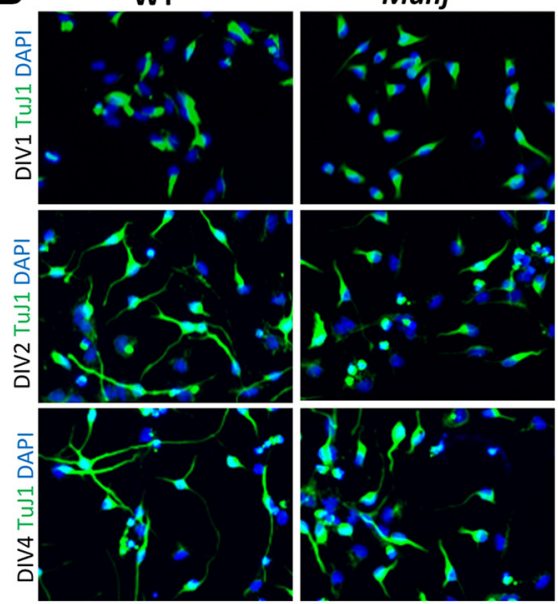

Manf ${ }^{-1-\text { rhMANF }}$

D
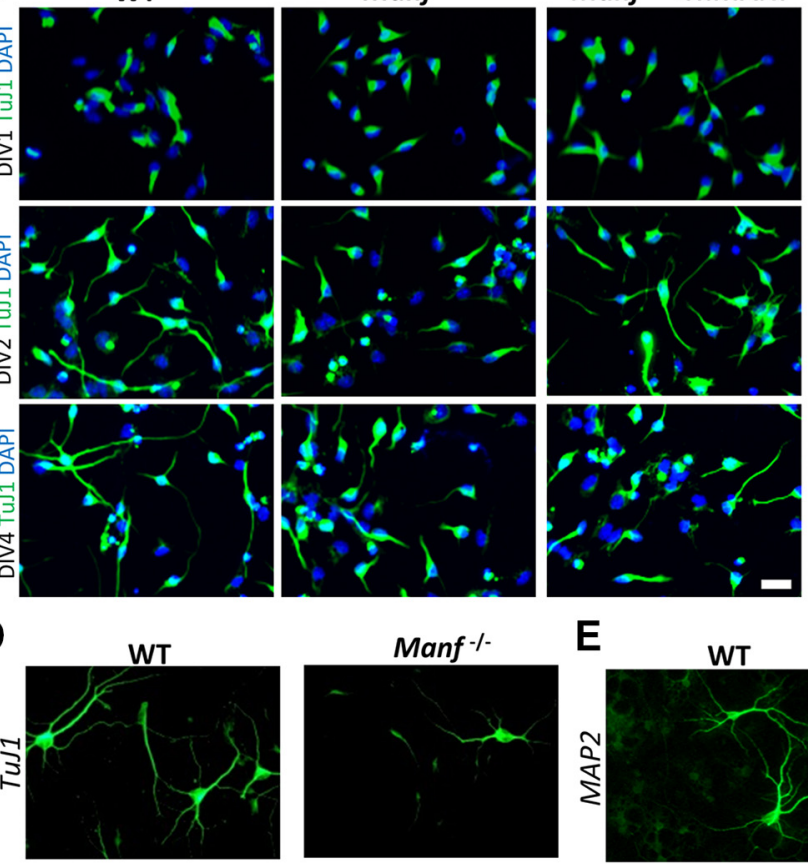

C $\quad-\quad$ WT
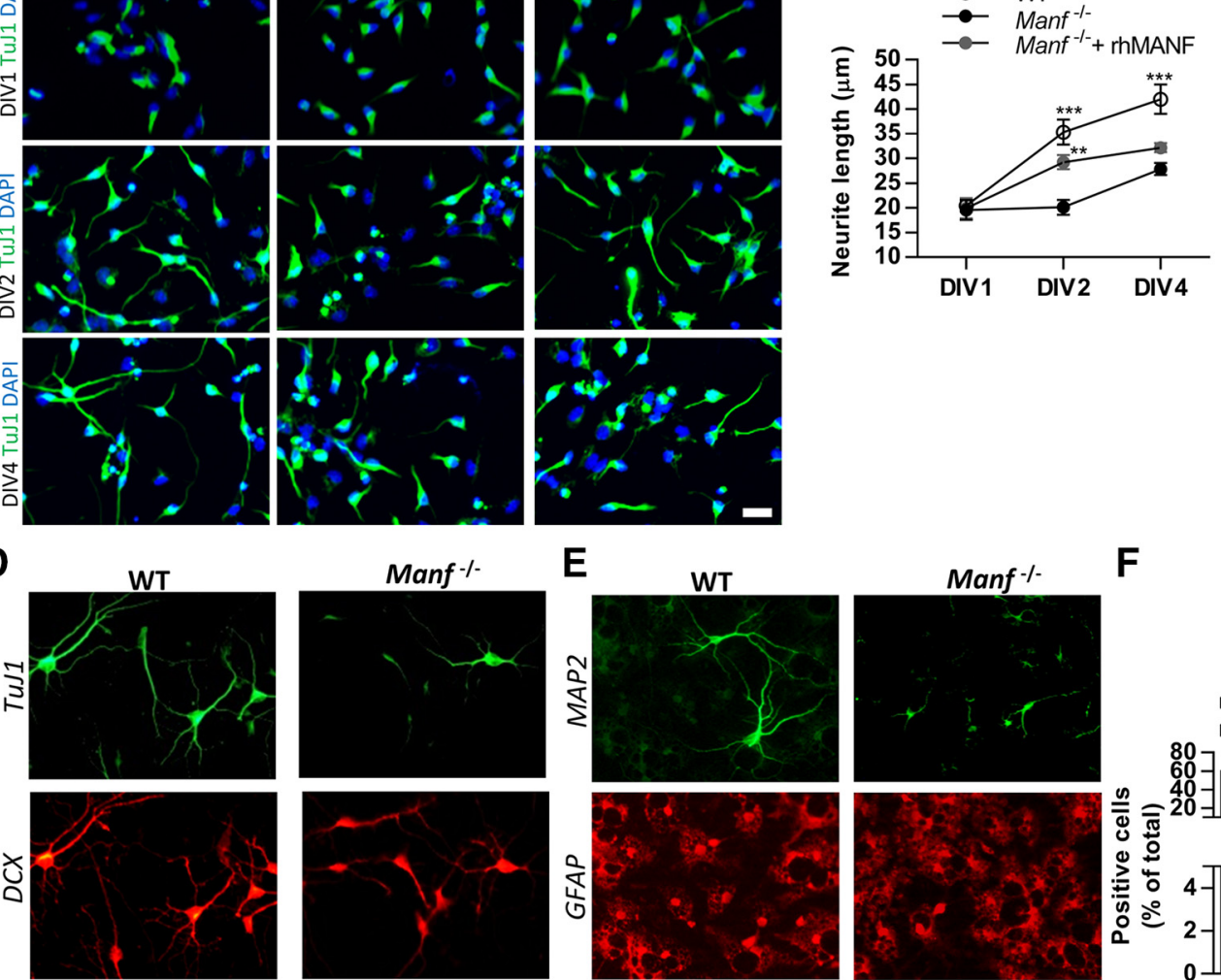

E
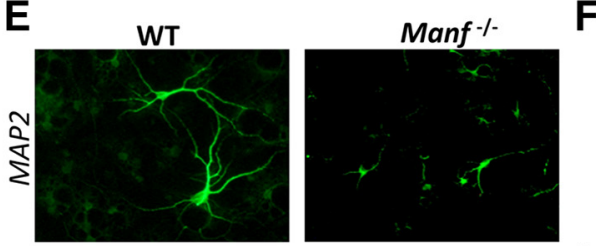

$\mathbf{F}$
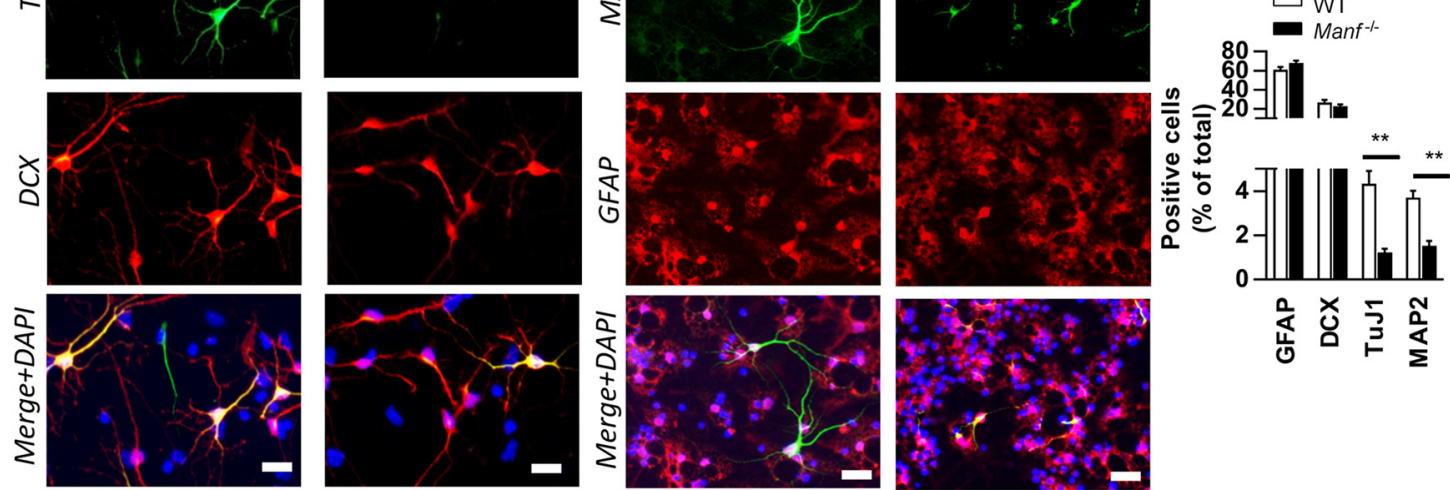

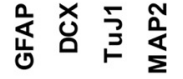

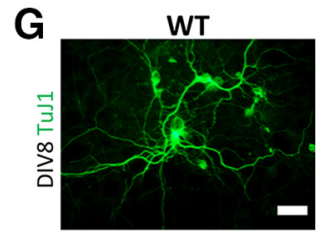

H
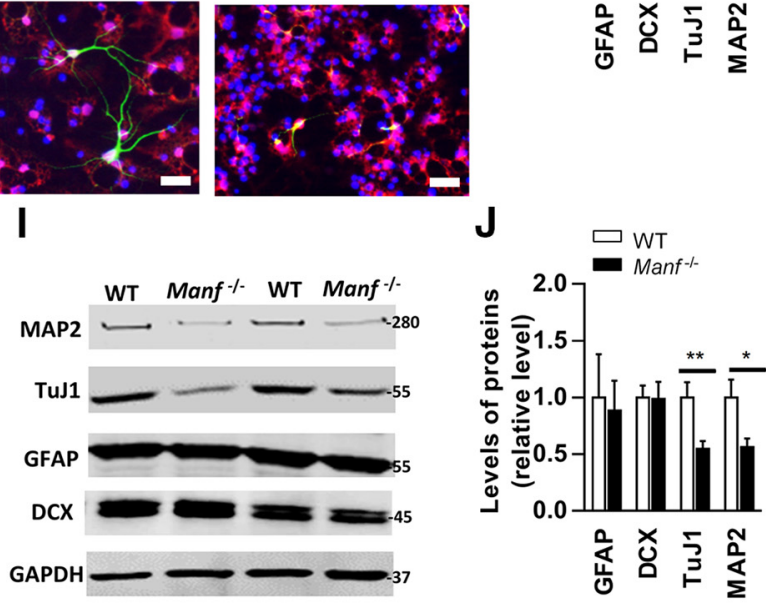

Figure 3. Effects of MANF on neuronal differentiation. $\boldsymbol{A}$, Time line of the differentiation of NSCs. NSC expansion was done for $1 \mathrm{~d}$ in floating conditions. At day 1, differentiation begun without EGF and FGF-2 for $7 \mathrm{~d}$ in adhering conditions. $\boldsymbol{B}$, At DIV1, DIV2, and DIV4, differentiated cells were stained with antibodies against neuronal markers TuJ1; scale bar; $50 \mu \mathrm{m}$. $\boldsymbol{C}$, Neurite length were measured from TuJ1-positive cells. Manf ${ }^{-/-}$cells displayed significantly shorter neurite length. Exogenous rhMANF induced neurite outgrowth at DIV2 but not at DIV4 of Manf $^{-/-}$cells, two-way ANOVA, post hoc Bonferroni test; $* * p<0.01, * * * p<0.001$; scale bar: 
continued

$50 \mu \mathrm{M} . \boldsymbol{D}, \boldsymbol{E}$, Representative photomicrographs of differentiated cells double-stained for TuJ1 (green), DCX (red), MAP2 (green), and GFAP (red), and nuclei stained with DAPI (blue); scale bar: $50 \mu \mathrm{M}$. $\boldsymbol{F}$, Ratios of GFAP-, DCX-, TuJ1-, and MAP2-positive cells in relation to DAPI+ nuclei $(n=9)$. $\mathbf{G}, \boldsymbol{H}$, At DIV8, neurite extension were measured from TuJ1-positive cells. Manf ${ }^{-/-}$cells displayed significantly shorter processes than WT cells $(n=9)$; scale bar: $20 \mu \mathrm{M}$. I, Lysates from WT and Manf ${ }^{-/-}$cells after differentiation were immunoblotted with MAP2, TuJ1, GFAP, DCX, and GAPDH antibodies. J, Protein levels were quantified in relation to levels of GAPDH, a housekeeping protein, $n=9 ; * p<0.05$, $* * p<0.01$, Student's $t$ test.

TBR2, respectively, in the VZ/SVZ at E15.5, revealed no difference between the WT and Manf $^{-/-}$group (Fig. 5E-H). To analyze programmed cell death, we performed immunohistochemistry for activated caspase-3. As depicted in Figure $5 /, J$, we found very few dying cells in sections from WT and $\mathrm{Manf}^{-/-}$neocortex. These data suggest that the deficits in the $\mathrm{Manf}^{-{ }^{-}}$neocortical development is not due to the number of NSCs/NPCs, cell proliferation rate, or programmed cell death.

\section{The distribution of CTIP2+, Tbr1+, and Cux1+ cells is altered in Manf $^{-/-}$neocortex}

To study how MANF deficiency influences cortex development, cortical sections from WT and $\mathrm{Manf}^{-{ }^{--}}$mice were

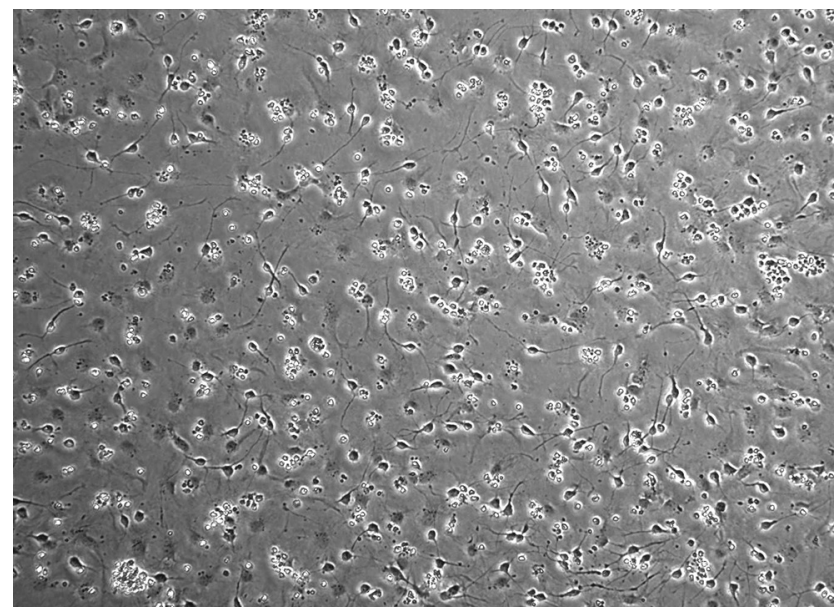

Video 1. Video of WT cells. [View online]

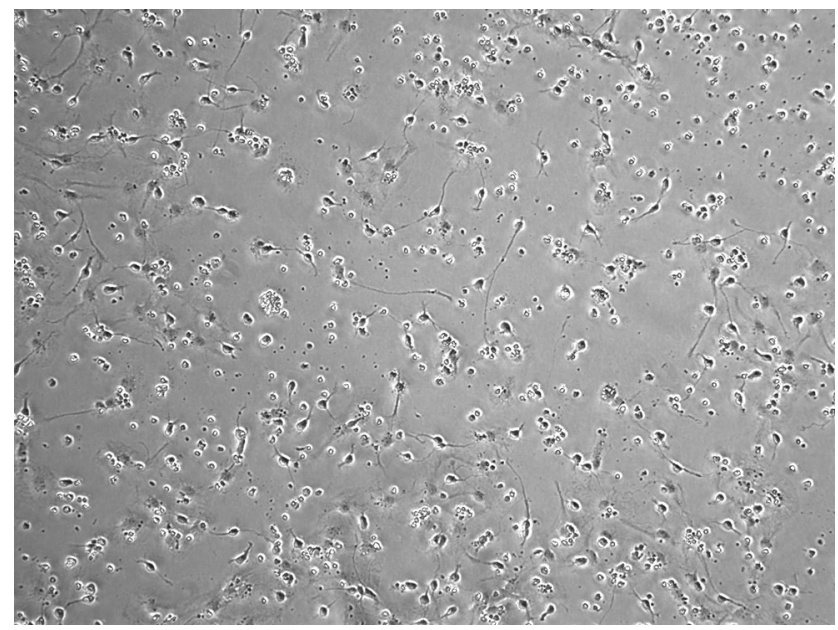

Video 2. Video of MANF-/- cells. [View online] stained with CTIP2, Tbr1, and Cux1: markers for neuronal specification in different layers during cortex development (Molyneaux et al., 2007; Bedogni et al., 2010). As expected, at E15.5, CTIP2 + cells were found in the whole CP while Tbr1 + cells were mainly found in the lower part in both genotypes (Fig. $6 A, B$ ). Moreover, the numbers of CTIP2+ and Tbr1 + neurons were similar in WT and Manf $^{-/-}$embryos (Fig. 6G,H). At E18.5, considerable Tbr1+ cortical neurons accompanied by scanty CTIP2 + neurons have been found at the lower layer of the cortex in WT embryos. In contrast, in $\mathrm{Manf}^{-/-}$embryos, there were fewer Tbr1+ neurons, but more CTIP2 + subcerebral projection neurons at the lower layer of the cortex (Fig. $6 A, B, G, H$ ). Moreover, the distributions of CTIP2 + and Tbr1+ neurons are partially intermingled in the mutant CP (Fig. 6D), unlike in WT embryos, having them being split into different layers, implying that many subcerebral neurons in Manf $^{-{ }^{-}}$embryos did not migrate to their destined positions or did not yet acquire layerspecific identification. At P1 and P7, the total number of CTIP2+ and Tbr1+ neurons in Layers V/NI were similar between the two genotypes.

We next analyzed Cux1+ neurons in developing cortex. Cux $1+$ cells are found in SVZ from E14.5 onwards, and during postnatal days, Cux1+ cells migrate to Layers II-IV (Cubelos et al., 2010). At E15.5, there were few Cux1+ neurons in the CP in both WT and Manf $^{-/-}$embryos (Fig. 6C). At E18.5, many of the Cux1+ neurons were found in the upper layer of CP in WT mice. However, in $\mathrm{Manf}^{--}$mice, there were fewer Cux1+ neurons in the CP compared to WT littermates (Fig. 6C,I). Also, different to the WT group, with a clear distribution of subtype neurons, in mutant embryos Cux1+ and CTIP+ neurons were dispersed in the CP, revealing a disordered neuronal arrangement (Fig. 6E). At P1, more Cux $1+$ neurons were found in the deeper layers in Manf $^{{ }^{-/}}$mice than in WT littermates, implying that Manf ${ }^{-1-}$ neurons had a delay in radial migration (Fig. $6 C, I)$. At P7, the total number of Cux1+ neurons was similar between the genotypes and the arrangement of $\mathrm{Manf}^{-/-}$cortical neurons was fully recovered due to higher cell density observed at the Layers II-IV owing to a thinner cortex in mutant mice. Taken together, these findings suggest that the thinner CP accompanied by the abnormal distribution of cortical layer markers in $\mathrm{Manf}^{-/-}$embryos might be caused by slower neuronal migration and disturbed subtype neuron specification.

\section{Delayed neuronal migration in MANF-deficient embryos}

To examine whether MANF regulates neuronal migration in the cerebral cortex, we used BrdU birth dating. We first labeled the early-generated neurons by injecting 


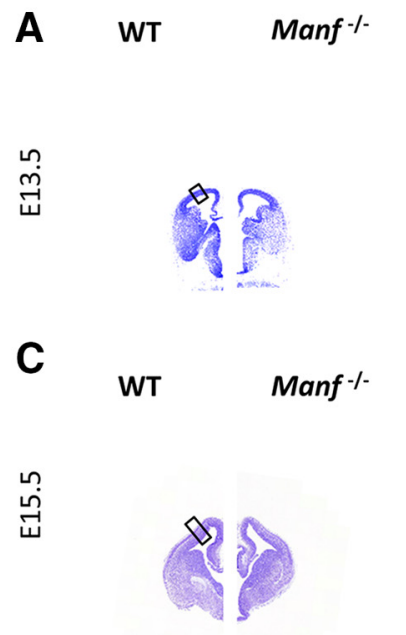

\section{B WT}

E13.5

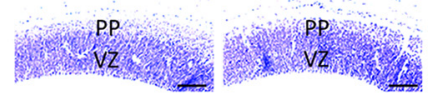

D WT
E15.5

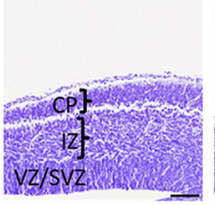

E

WT

Manf $/-$

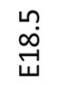

G

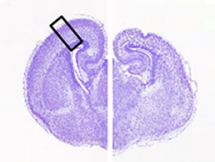

WT

Manf ${ }^{-/}$

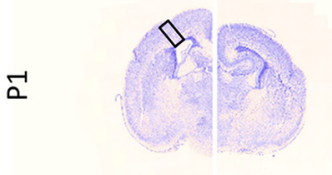

I

WT

Manf ${ }^{-/}$
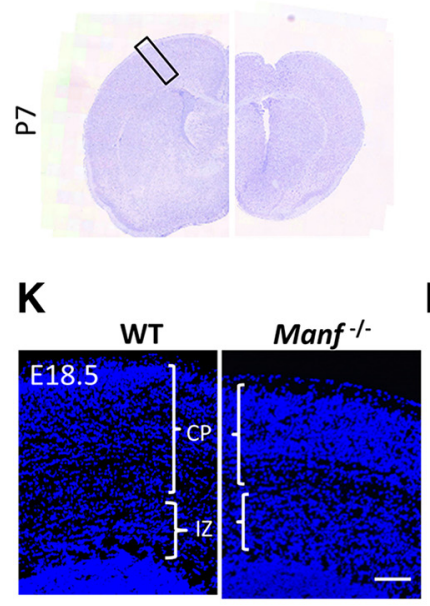

F WT

E18.5

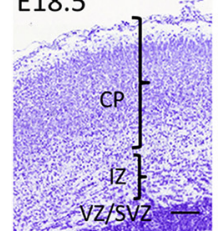

H

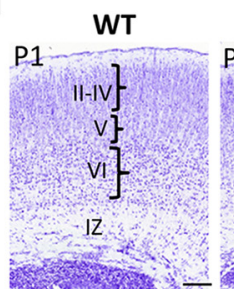

J

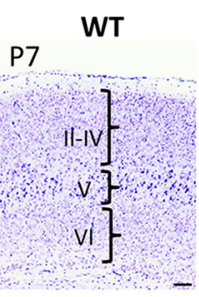

L

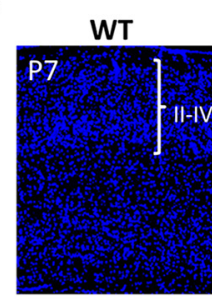

Manf ${ }^{-/}$

E13.5 E15.5

Manf ${ }^{-/}$

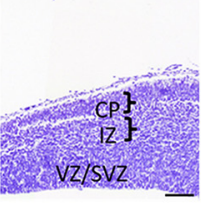

Manf $\%$

E18.5
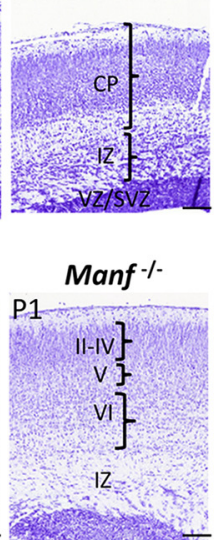

P7

Manf $\%$
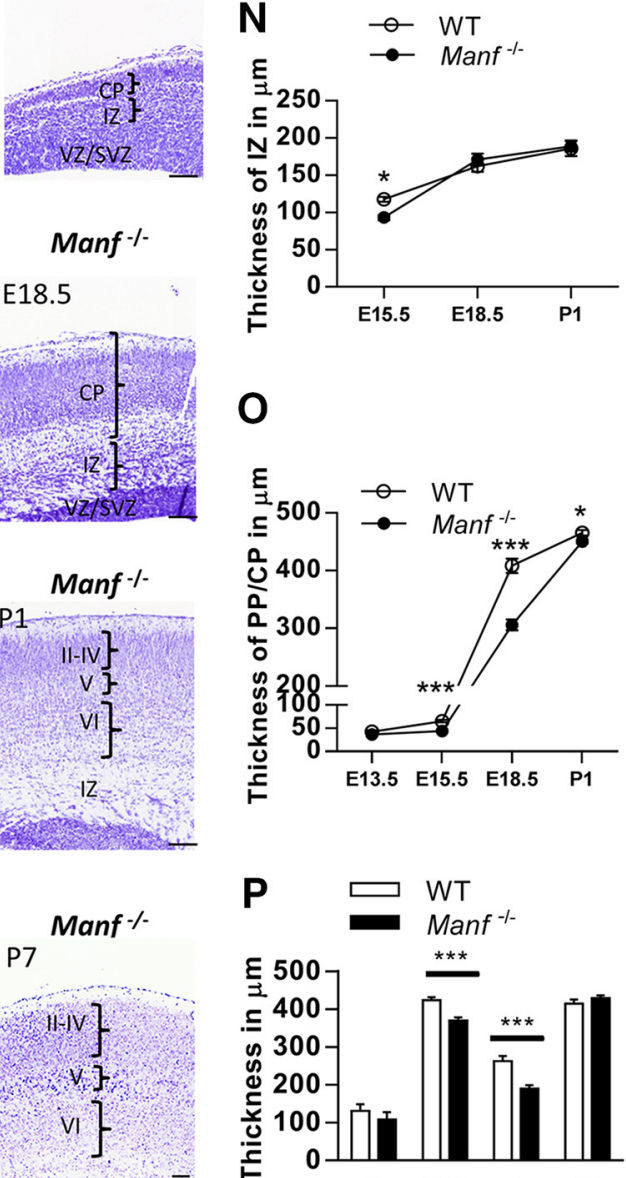

0
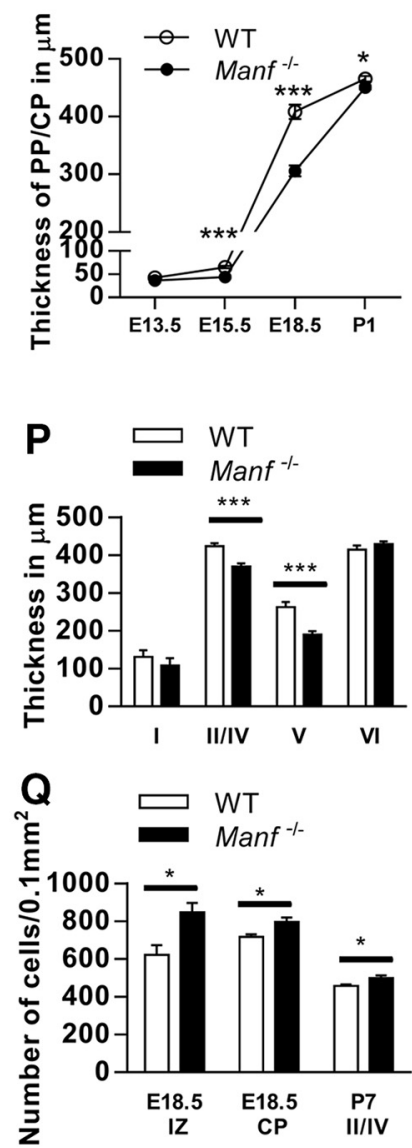

Figure 4. Morphologic alteration of embryonic and early postnatal cortex in WT and Manf ${ }^{-/-}$mice. A-J, Coronal sections of the developing cortex stained with Nissl. $\boldsymbol{A}, \boldsymbol{B}$, There is no difference in the overall appearance of the cortex between WT and Manf ${ }^{-/-}$mice at E13.5. $\boldsymbol{C}, \boldsymbol{D}$, At E15.5, the IZ and CP are thinner in the Manf ${ }^{-/-}$mice than in WT littermates, but the thickness of SVZ/VZ is not changed. $\boldsymbol{E}, \boldsymbol{F}$, At E18.5, the CP is thinner in Manf $^{-/-}$mice compared to WT mice. G-J, At P1 and P7, the cortex layer is thinner, prominently at Layer II-V in Manf ${ }^{-/-}$mice compared to controls. $\boldsymbol{K}$, At E18.5, the cell density in the CP is higher in the Manf ${ }^{-/-}$mice compared to WT mice (blue, DAPI). L, At P7, DAPI+ nuclei in the cortex Layer II-IV is higher in Manf ${ }^{-/-}$mice compared to WT mice. $\boldsymbol{M}$, There was no difference in VZ/SVZ thickness between WT and Manf $^{-/-}$embryos or pups at any time point studied. $\boldsymbol{N}$, The thickness 
continued

of IZ was significantly reduced at E15.5 in the Manf ${ }^{-/-}$, but recovered by E18.5 ( $\boldsymbol{L}$, *p $<0.05$, Student's $t$ test). $\boldsymbol{O}$, The thickness of PP/CP was significantly reduced at E15.5, E18.5, and P1 in Manf ${ }^{-/-}$compared to WT littermates $(\boldsymbol{M}, * * * p<0.001, * * p<0.001, * p<$ 0.05 , respectively, Student's $t$ test). $\boldsymbol{P}$, The thickness of cortical layers was measured at P7, and we observed significantly thinner Layers II/IV and V in Manf ${ }^{-/-}$mice compared to WT littermates (***p $<0.001$, Student's $t$ test). $\mathbf{Q}$, Quantification of the DAPI+ nuclei; scale bars: $100 \mu \mathrm{m}$.

pregnant $\mathrm{Manf}^{+/-}$mice with BrdU at E13.5 and analyzed the embryos at E17 (Fig. 7A). Cortical sections from E17 embryos were stained with BrdU antibodies, and the number of BrdU + cells were quantified in each cortical layer. The number of BrdU+ cells detected in the CP and SP of $\mathrm{Manf}^{-/-}$embryos were significantly reduced compared to WT littermates (Fig. $7 A, B$ ). In contrast, the number of BrdU+ cells in VZ/SVZ of Manf ${ }^{-/}$embryos were significantly increased compared to WT. Next, we labeled later generated neurons by administering BrdU to pregnant $\mathrm{Manf}^{+/-}$females at E15.5 and BrdU-labeled nuclei were examined in the CP at E19 (Fig. 7C,D). Most BrdUlabeled nuclei were located at Layer II/III of WT cortex. However, in Manf $^{-/-}$cortex, more BrdU-labeled nuclei were found in Layers IV and V/VI (Fig. 7C,D). Thus, these two experiments indicate that radial migration of both early- and later-generated neurons is impaired in Manf $^{-/-}$ embryos. Moreover, we examined the overall architecture of radial glial fibers by Nestin staining and the expression patterns of Reelin, a matrix glycoprotein that regulates neuronal migration and positioning. We found that Nestin and Reelin immunofluorescence are similar in WT and Manf $^{-/-}$cortices at E15.5 (Fig. 7E,F) suggesting that the deficits in neuronal migration and positioning are characteristic of immature Manf $^{-/-}$neurons. Overall, these results suggest that MANF is essential for migration of neurons in the embryonic cortex.

\section{Decreased neurite extension and abnormal neuronal architecture in the Manf $^{-/-}$cortex}

Considering that loss of MANF caused reduced thickness of the cortical layer, we investigated whether the lack of MANF decreases the number of neurons or glial cells at E19 and P7. At E19 when cortical lamination is being developed, few NeuN-positive neurons and MAP2-positive dendrites were located in the CP (Fig. 8A,B). The fluorescent signal intensities of NeuN and MAP2 in relation to the area of CP showed no significant differences between the two genotypes (Fig. $8 C$ ), suggesting that loss of MANF does not affect the generation of cortical neurons. Similarly, Western blot analysis showed that NeuN and MAP2 levels from E19 CP tissues were similar between the genotypes (Fig. 8D,E). Additionally, GFAP levels were similar between genotypes, but surprisingly, the level of neurofilament (NF200) was significantly lower in Manf $^{-/-} \mathrm{CP}$. Since neurofilament exerts a regulatory function in cell structure, axonal transport and stabilization (Lariviere and Julien, 2004), these data might support the role of MANF in axon outgrowth during later cortical development. At P7 we found no difference in the number of $\mathrm{NeuN}+$ neurons between the two genotypes (Fig. 8F). However, when investigating the neuronal distribution in the cortex, we found increased NeuN density in the Lay- ers II-V, but not Layer VI, of the Manf ${ }^{-/-}$cortex (Fig. $8 F, G$ ). Additionally, the fluorescent intensity of GFAP was similar in the two genotypes (Fig. 8H). While there was no difference in MAP2 fluorescent intensity between the genotypes (Fig. 8I,J), Manf ${ }^{-/-}$neurons displayed shorter MAP2stained dendrite extensions compared to WT littermates (Fig. 8J). Further, axons from Manf ${ }^{--}$cortex stained less intensely with the neurofilament marker compared to WT axons (Fig. 8K,L). In line with the above results, the levels of GFAP, MAP2, and NeuN in Western blotting were similar between the two genotypes (Fig. $8 M, N$ ). The NF200 level was reduced in Manf $^{-1-}$ cortex compared to WT at P7 (Fig. 8M,N). Overall, these findings suggest that loss of MANF does not decrease the number of cortical neurons or glial cells, but results in decreased neurite extension as well as axon-specific cytoskeletal protein levels, and abnormal neuronal density in the developing cortex.

\section{Loss of MANF results in activated UPR but not increased apoptosis during NSC differentiation}

Previous studies have indicated that MANF is upregulated in ER stress conditions in vitro (Apostolou et al., 2008; Glembotski et al., 2012) and lack of MANF leads to chronic UPR activation in pancreatic islets in vivo (Lindahl et al., 2014). It has also been shown that dysregulation of UPR can cause defects in neurogenesis and neuronal maturation and that these mechanisms could underlie neurodevelopmental disorders (Godin et al., 2016). Therefore, we wanted to investigate whether increased ER stress and activated UPR also appear in $\mathrm{Manf}^{-/-} \mathrm{NSCs}$ and measured the expression levels of UPR genes Grp78, Atf4, Atf6a, spliced Xbp1, and Chop, which are known to increase under ER stress conditions. In undifferentiated NSCs there was no difference in the levels of mRNAs for Chop, spliced Xbp1, total Xbp1, Atf4, Atf6a, and Grp78 (alias Bip) between the $\mathrm{Manf}^{-/}$group and WT controls (Fig. 9A). However, at DIV1, the level of spliced Xbp1 mRNA expression was higher in the $\mathrm{Manf}^{-/}$group, followed by increased Grp78 at DIV4 $(p<0.05$, Student's $t$ test; Fig. 9B,C). At DIV8, significant elevation of mRNA levels for Grp78, Atf4, and spliced Xbp1 were found in Manf $^{-/-}$differentiated cells (Fig. 9D). Moreover, quantification of p-elF2 $\alpha$ band intensities compared to total levels of (t)elF2 $\alpha$ by Western blot analysis revealed a higher level of p-elF2 $\alpha$ compared to total EIF2 $\alpha$ in Manf $^{-/-}$NSCs at DIV8 (Fig. 9E,F). Collectively, these studies show that when Manf $^{-/-}$NSCs start to differentiate, Grp78 and spliced Xbp1 mRNA in the inositol-requiring enzyme 1 (IRE1) pathway are upregulated, followed by increased phosphorylation of elF2 $\alpha$ protein and Atf 4 mRNA demonstrating the activation of the protein kinase RNA-like ER kinase (PERK) pathway. Meanwhile, Atf6a or Chop mRNA 

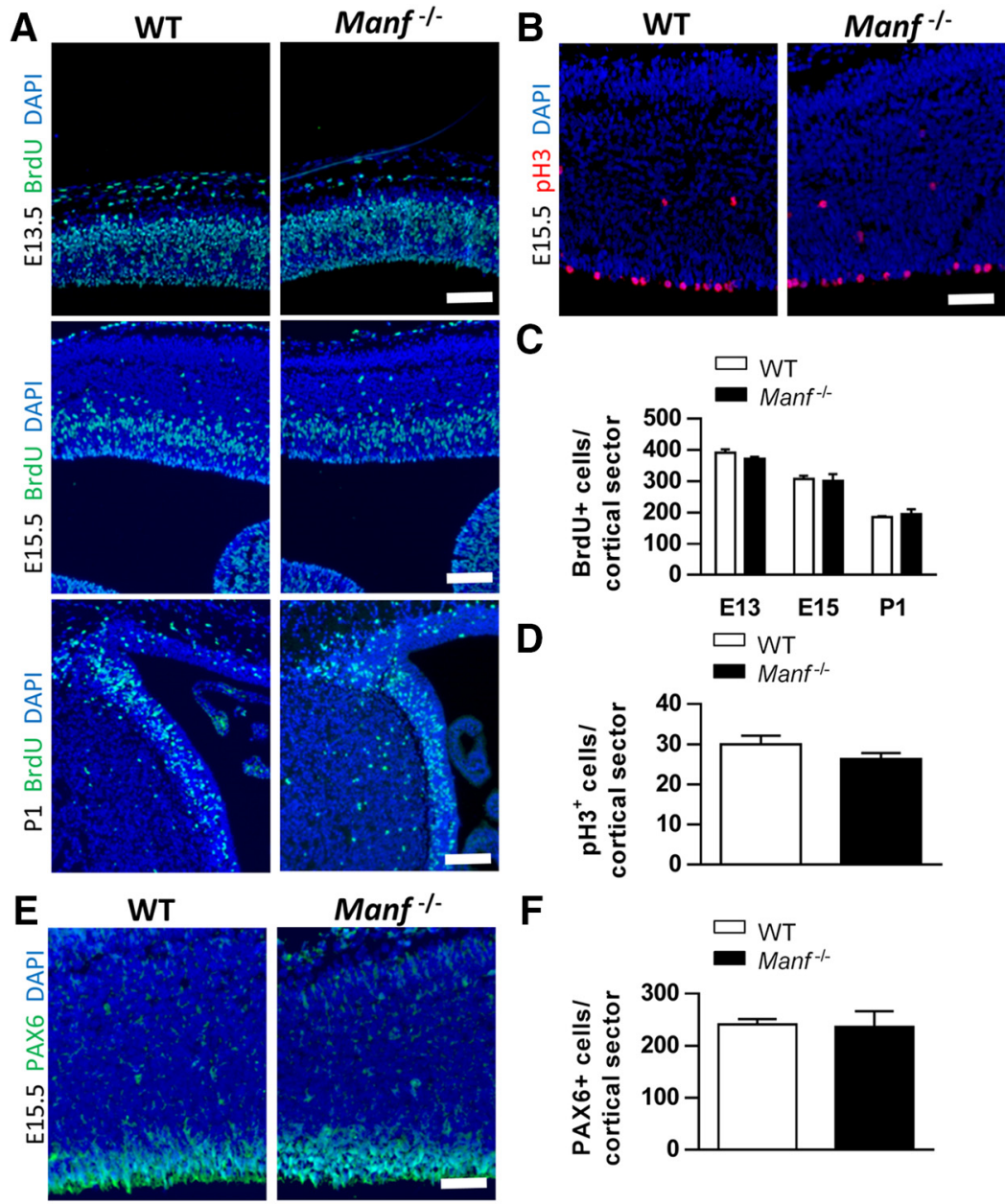

F
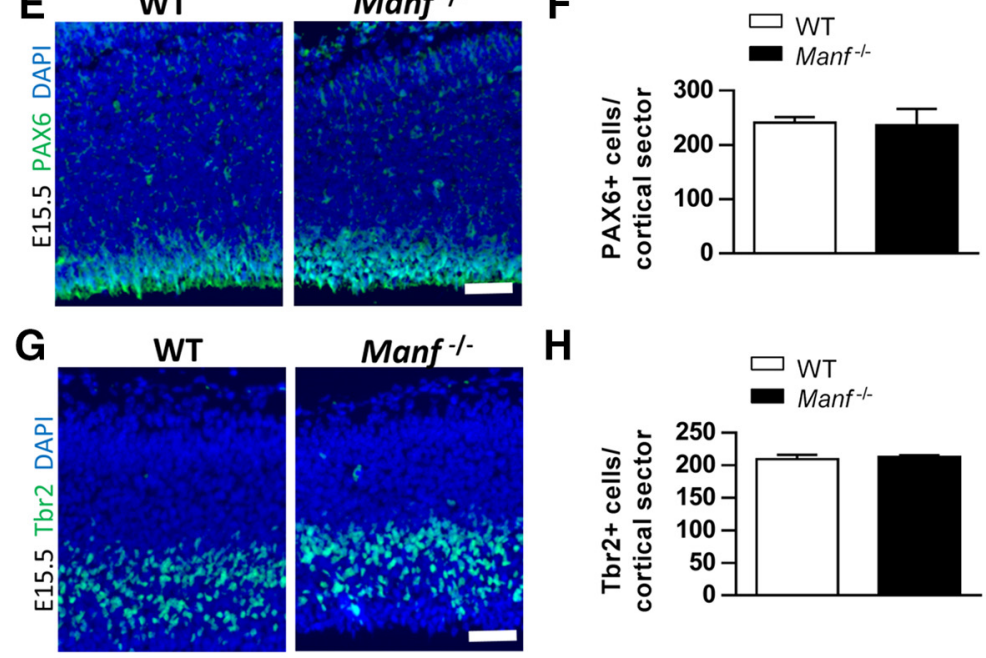

H
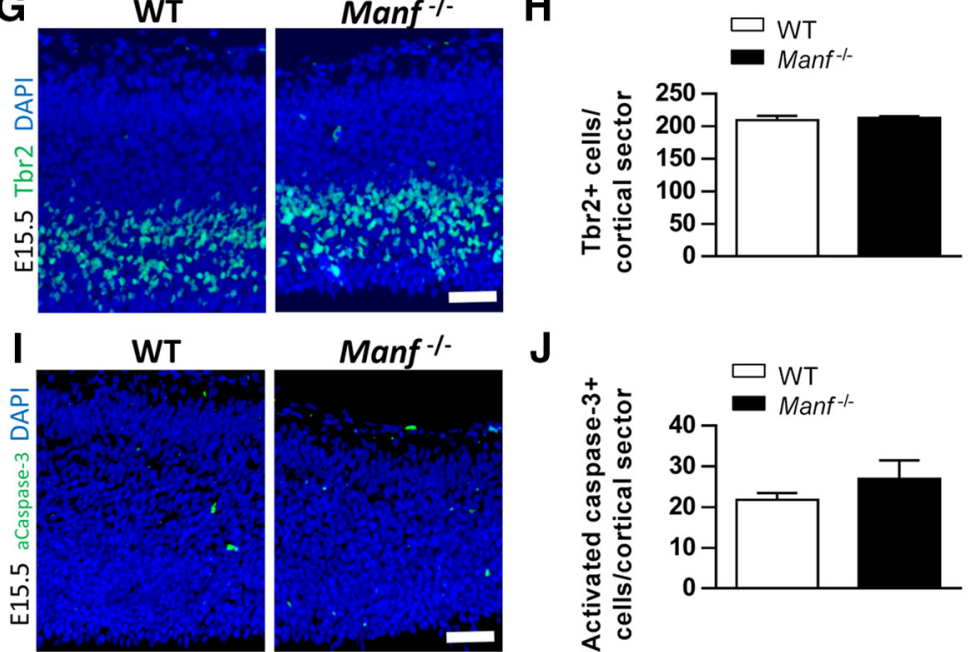

Manf $\%$

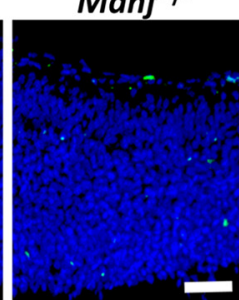

J

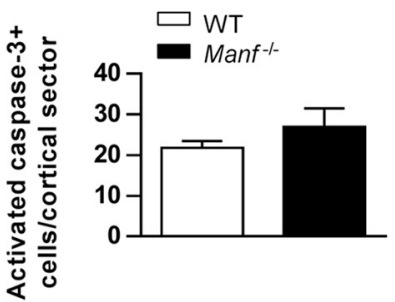

Figure 5. Loss of MANF does not affect the proliferation or survival of neural precursors. A, C, Analysis of S-phase progenitor cells by BrdU pulse labeling of WT and Manf $^{-/-}$embryos at E13.5, E15.5, and P1. A similar number of S-phase cells are in the Manf ${ }^{-/-}$cortex relative to the WT littermates. The average number of BrdU-labeled cells in the SVZ was calculated at E13.5, E15.5, and P1. $\boldsymbol{B}, \boldsymbol{D}, \mathrm{The}$ number of $\mathrm{pH} 3$-positive cells in the VZ/SVZ of E15.5 Manf $^{-/-}$mice is not different from WT littermates. The number of PAX6-positive cells $(\boldsymbol{E}, \boldsymbol{F})$ or Tbr2-positive cells $(\boldsymbol{G}, \boldsymbol{H})$ in the cortex did not differ between WT and Manf ${ }^{-/-}$brains. $\boldsymbol{I}$, J, Very few apoptotic cells were found in cerebral cortex from E15.5 WT as well as Manf ${ }^{-/-}$mice immunostained with activated caspase-3. Cell nuclei were counterstained with DAPI (blue). Data are expressed as the mean \pm SEM, $n=3-4$; scale bars: $50 \mu \mathrm{m}(\boldsymbol{A})$ and $100 \mu \mathrm{m}(\boldsymbol{B}, \boldsymbol{E}, \mathbf{G}, \boldsymbol{I})$. 
A
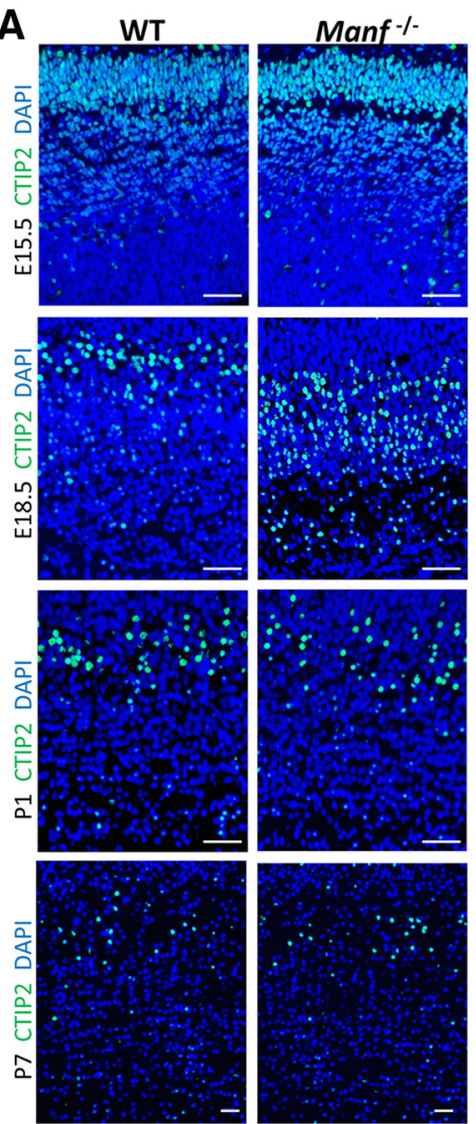

D

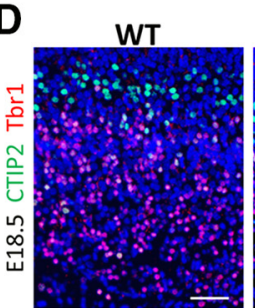

G
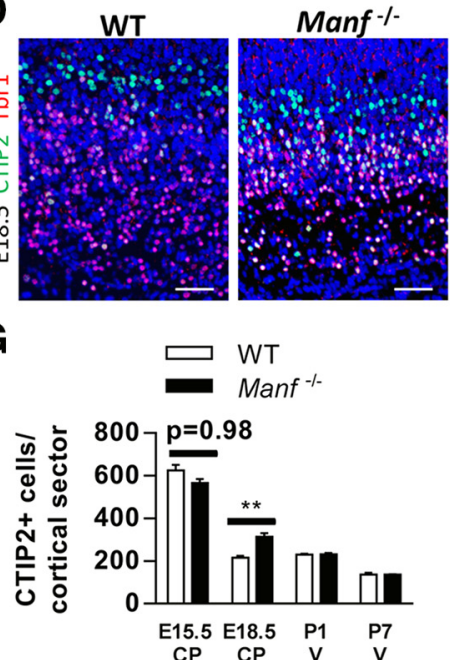
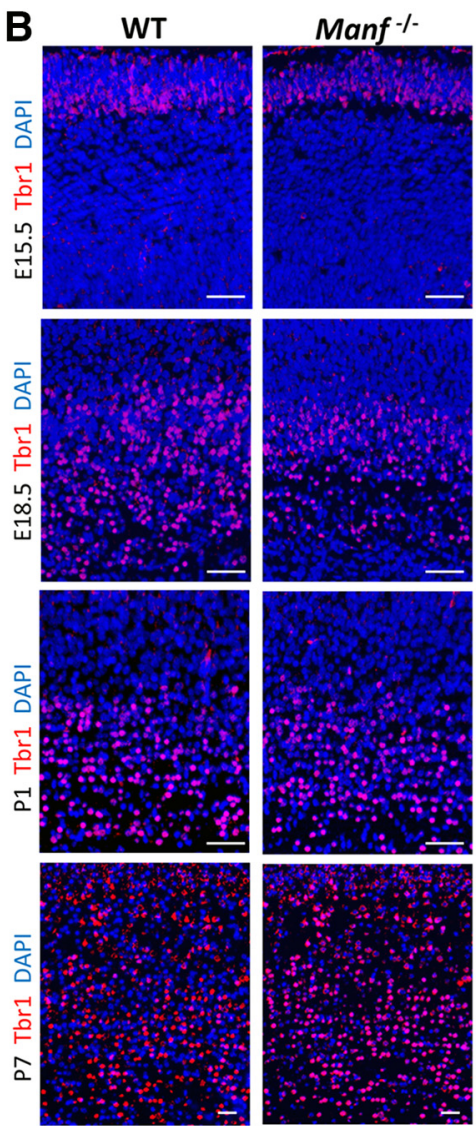

E

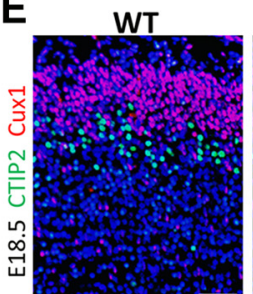

H

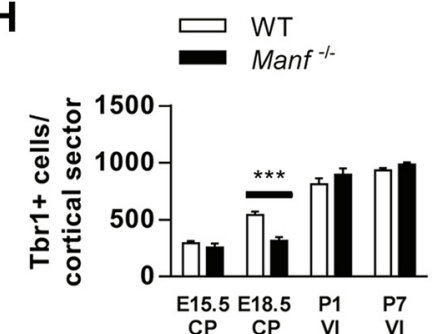

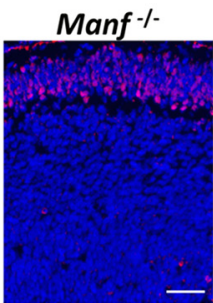
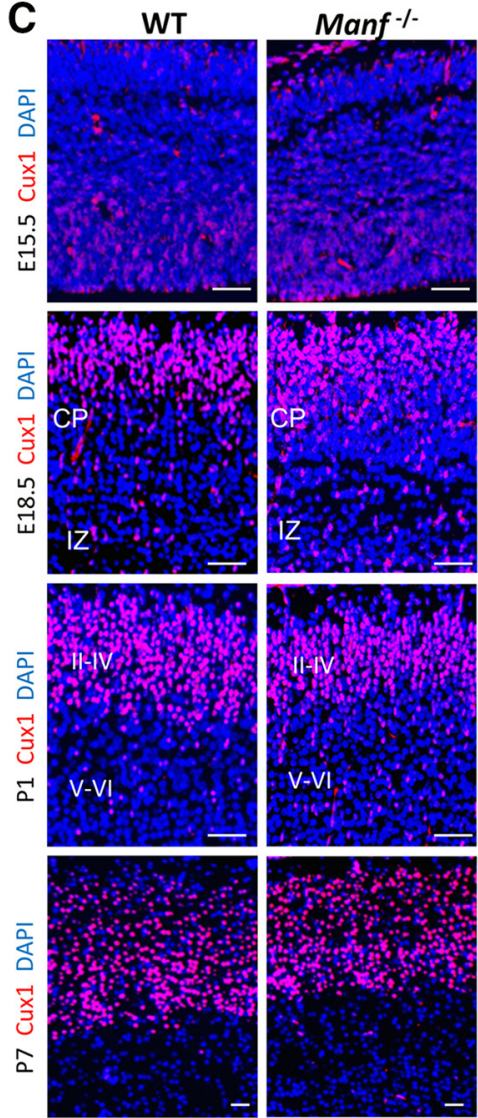

F
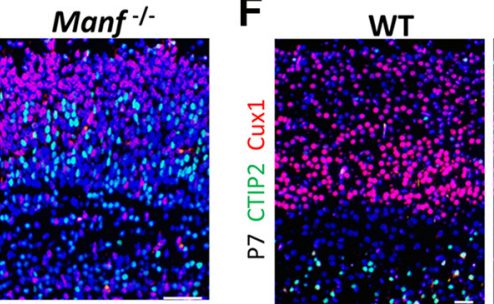

Manf -1

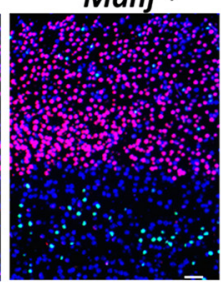

I

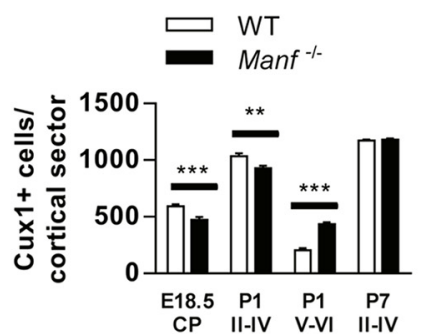

Figure 6. Distribution of cortical layer markers CTIP2, TBR1, and Cux1. A, The number of CTIP2+ cells at E15.5 are similar between WT and Manf $^{-/-}$in CP. At E18.5, there is a significant increase in CTIP2+ neurons density at deep layers of CP in the Manf ${ }^{-/-}$compared to the WT littermates, but there is no difference at P1 and P7. B, Tbr1 is located at the lower CP in the WT controls and Manf ${ }^{-/-}$mice at E15.5. In the Manf $^{-/-}$brain, there is a significant decrease in the number of Tbr1+ neurons in the deep layer of CP at E18.5 compared to WT controls, but there is a full recovery by P1 and P7. C, At E15.5, Cux1 is located at the VZ/SVZ, but is absent in the CP in WT and Manf ${ }^{-/-}$brain. There are fewer Cux1+ neurons in the superficial CP at E18.5 and Layers II-IV at P1 of Manf ${ }^{-/-}$brain than in WT controls. In the Manf ${ }^{-/-}$mouse brain, more Cux1-positive neurons remained in the IZ at E18.5 and in the Layers V and VI at P1. At P7, there is no difference in Cux1-positive neurons in the cortex between the genotypes. $\boldsymbol{D}$, Representative photomicrographs of E18.5 CP stained for Tbr1 (red), CTIP2 (green), and nuclei (DAPI, blue). $\boldsymbol{E}$, Representative photomicrographs of E18.5 CP stained for Cux1 (red), CTIP2 (green), and nuclei (DAPI, blue). $\boldsymbol{D}$, Representative photomicrographs of P7 cortex stained for Tbr1 (red), CTIP2 (green), and nuclei (DAPI, blue). G, The number of CTIP2 + cells in the CP at E15.5 and E18.5 and Layer V at P1 and P7 $(n=3 ; * * p<0.01)$. $\boldsymbol{H}$, The number of Tbr1+ neurons in the CP at E15.5 and E18.5 and at Layer VI at P1 and P7 $(n=3 ; * * * p<0.001)$. I, The number of Cux1+ neurons in the CP at E18.5; Layers II-VI, V-VI at P1 and P7 $(n=3 ; * * p<0.01, * * * p<0.001)$; scale bar: $100 \mu \mathrm{m}$. 
A

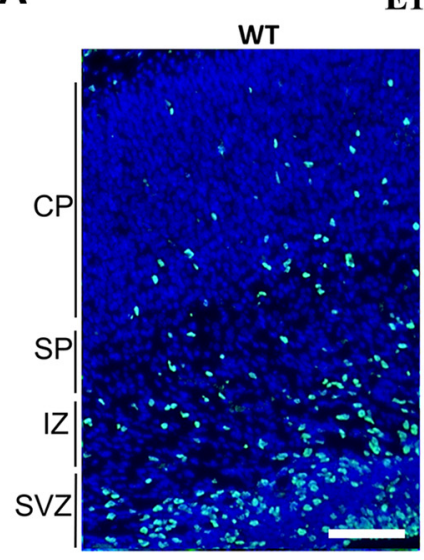

E13.5-E17

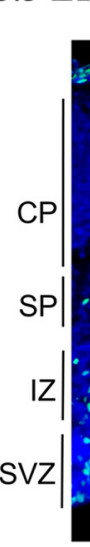

E15.5-E19
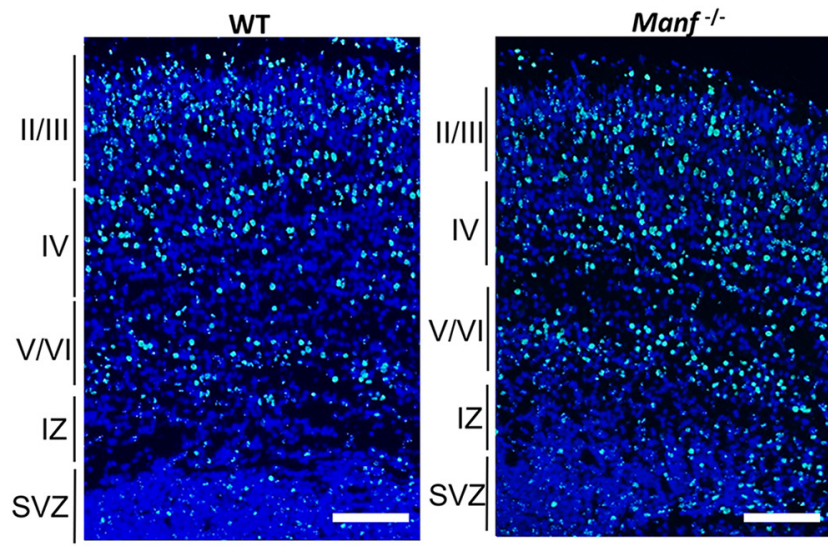

$\mathbf{E}$
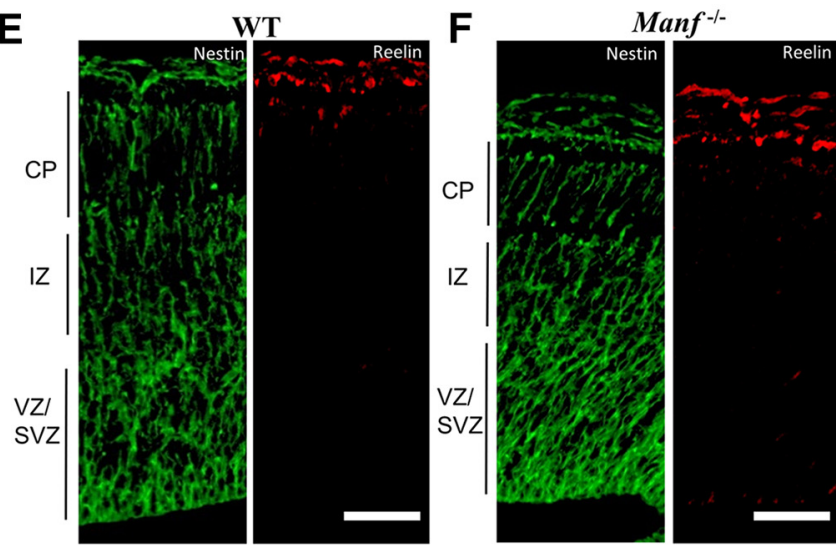

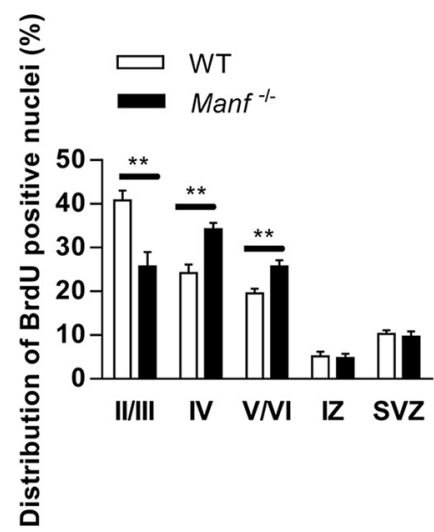

B

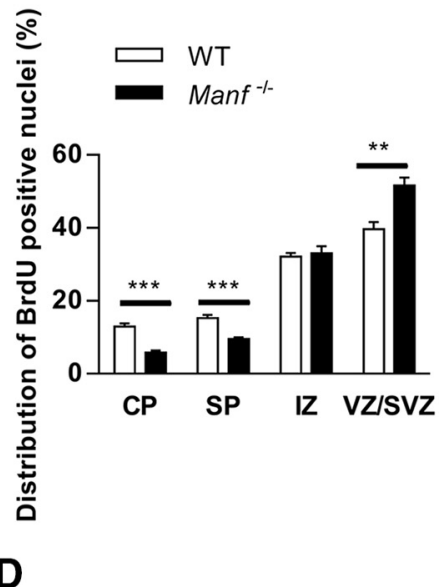

Figure 7. Radial migration of early (E13.5) and later (E15.5) born neurons in the neocortical regions with BrdU birth dating. $\boldsymbol{A}$, BrdU immunofluorescence staining of E17 cortex (BrdU administrated to pregnant Manf ${ }^{+/-}$mice at E13.5). B, The number of BrdU-labeled cells in each layer was counted and shown as percentages of total labeled cells number in the neocortex. The relative number of BrdU-positive cells were found to be decreased in CP and SP of Manf ${ }^{-/}$mice compared to WT littermates, and increased levels in VZ/SVZ $(n=3 ; * * p<0.01, * * * p<0.001)$. $\mathbf{C}$, BrdU was administered at E15.5 and the distribution of the labeled cells was examined at E19. In the WT cortex, increased number of labeled cells (green) were found in in the Layers II/III compared to that in Manf $^{-/-}$cortex. In contrast, increased number of BrdU-positive cells were found in the cortical Layers IV and V/VI in the Manf $^{-/-}$mice compared to the WT mice. $\boldsymbol{D}$, To quantify the distribution of BrdU-positive nuclei, the cerebral cortex was divided into five area from the pial side to the ventricular side. The number of labeled cells in each bin was counted and shown as percentages of total labeled cells number in the CP $\left(n=3, * p<0.05, * * * p<0.001\right.$ for Manf ${ }^{-/-}$mice compared to WT). Nuclei were counterstained with DAPI (blue). $\boldsymbol{E}, \boldsymbol{F}$, Immunofluorescent staining of coronal sections of neocortex with anti-Nestin and anti-Reelin antibodies. Radial glial architecture and Reeling expression in were similar in WT and in mutants; scale bars: $50 \mu \mathrm{m}(\boldsymbol{A}, \boldsymbol{C})$ and $25 \mu \mathrm{m}(\boldsymbol{E}, \boldsymbol{F})$. 
A

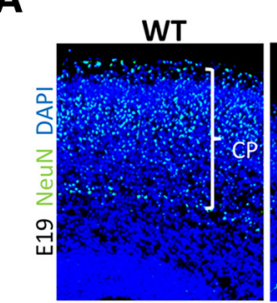

D

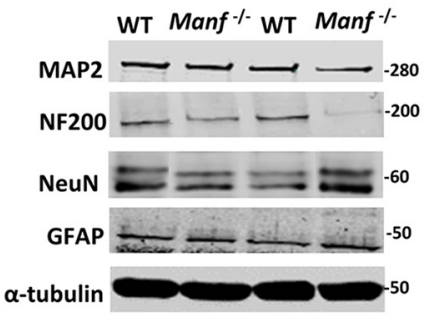

G

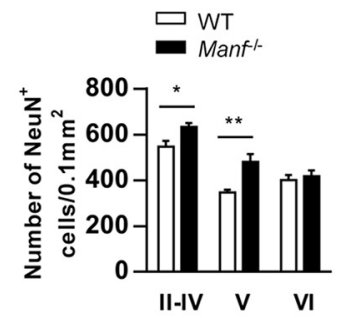

J

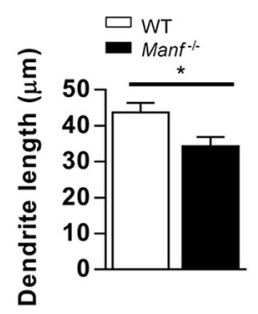

M

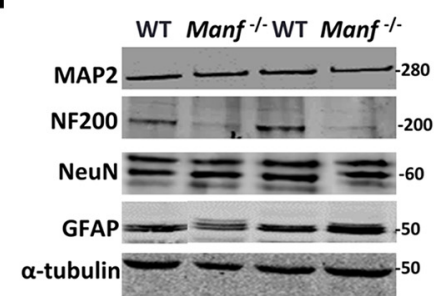

B

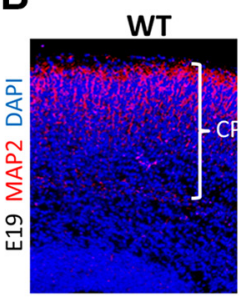

E

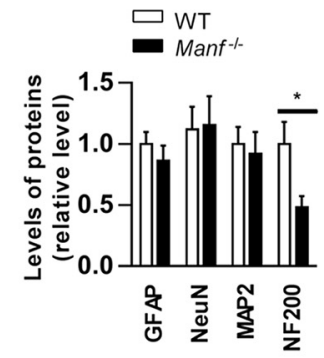

H

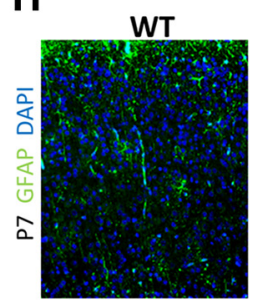

K

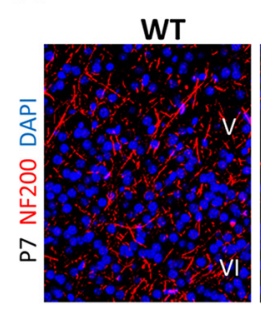

N

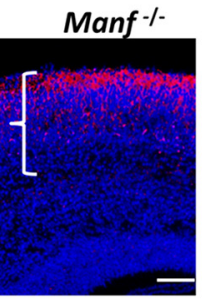

$F$

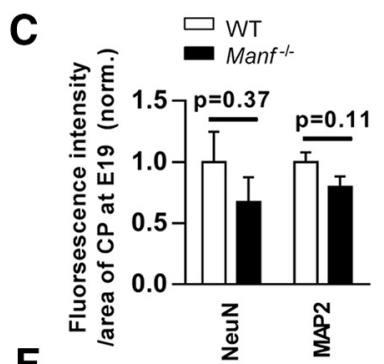

1

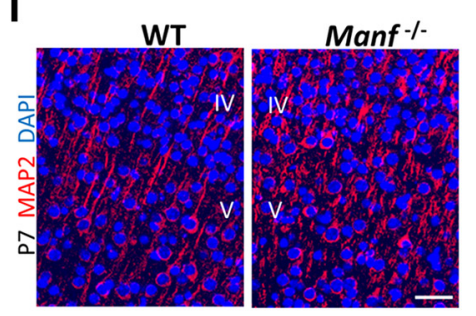

L

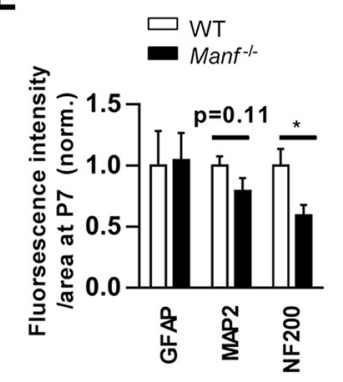

Figure 8. NeuN, GFAP, MAP2, and NF200 expression in the developing cortex. $\boldsymbol{A}, \boldsymbol{B}$, Representative photomicrographs of WT and Manf ${ }^{-/-}$ cortical sections stained with $\operatorname{NeuN}(\boldsymbol{A})$ or MAP2 $(\boldsymbol{B})$ at E19, and counterstained with DAPI (blue) at E19. $\boldsymbol{C}$, The fluorescent intensities divided by the area of CP. There is no difference between WT and Manf ${ }^{-/-}$embryos in the NeuN and MAP2 fluorescent intensities/area of CP $(n=$ 3). $\boldsymbol{D}, \boldsymbol{E}$, Western blotting from E19 cortical lysates stained with antibodies against NeuN, MAP2, GFAP, and NF200 ( $n=4, * p<0.05)$. $\boldsymbol{F}$, Representative photomicrographs of anti-NeuN (green) antibody-stained cortical sections of WT and Manf ${ }^{-/-}$mice at P7, counterstained with DAPI (blue). G, The density of NeuN-positive neurons in cortical layers at P7. In the Manf $^{-/-}$mouse brain there is a significant increase in NeuN-positive neuronal density in the Layers II-IV and V at P7 $(n=3, * p<0.05, * * p<0.01)$. $\boldsymbol{H}$, Representative photomicrographs of

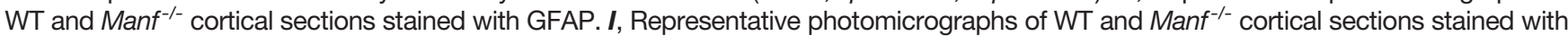
MAP2. J, Shorter MAP2-stained dendrites were found in Manf ${ }^{-/}$cortical neurons at Layer IVN of cortex compared to those in WT $(n=3$, $* p<0.05)$. $K$, Layer V/VI of cortex from Manf $^{-/-}$and WT littermates stained with neurofilament antibody (NF200). Cell nuclei were counterstained with DAPI. $L$, At P7, there is no difference in immunofluorescence intensities of MAP2 and GFAP-stained cortical sections between groups. However, there was a significant decrease in axon-specific neurofilament immunoreactivity in $M a n f^{-/-}$cortex $(n=3$, $* p<0.05)$. $\boldsymbol{M}, \boldsymbol{N}$, Western blotting from P7 cortical lysates probed with glial and neuron-specific antibodies. Decreased levels of NF200 was detected in the cortical extracts from Manf $^{-/-}$mice $(n=4, * p<0.05)$; scale bars: $50 \mu \mathrm{m}(\boldsymbol{A}, \boldsymbol{B}, \boldsymbol{F}, \boldsymbol{H})$ and $25 \mu \mathrm{m}(\boldsymbol{I}, \boldsymbol{K})$. 
A

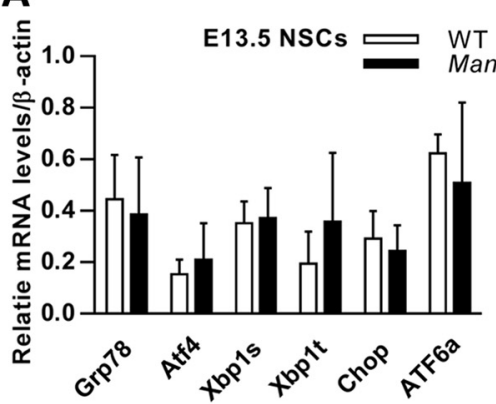

D

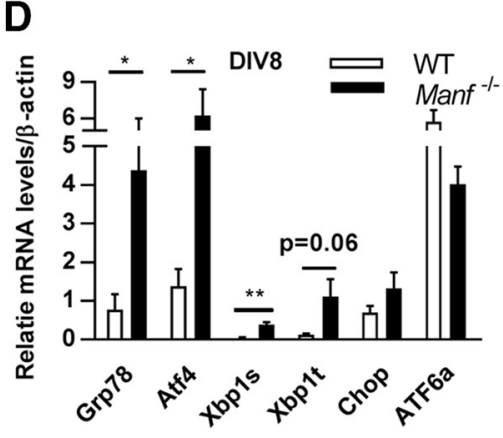

G

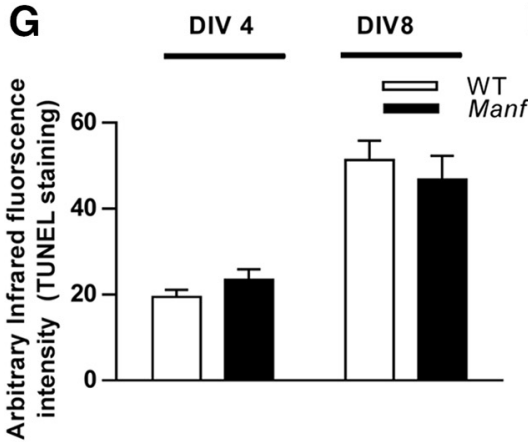

H

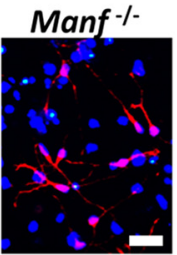

E

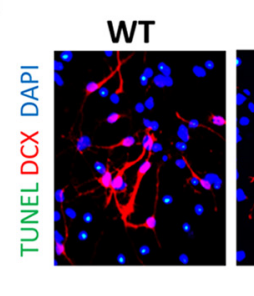

C
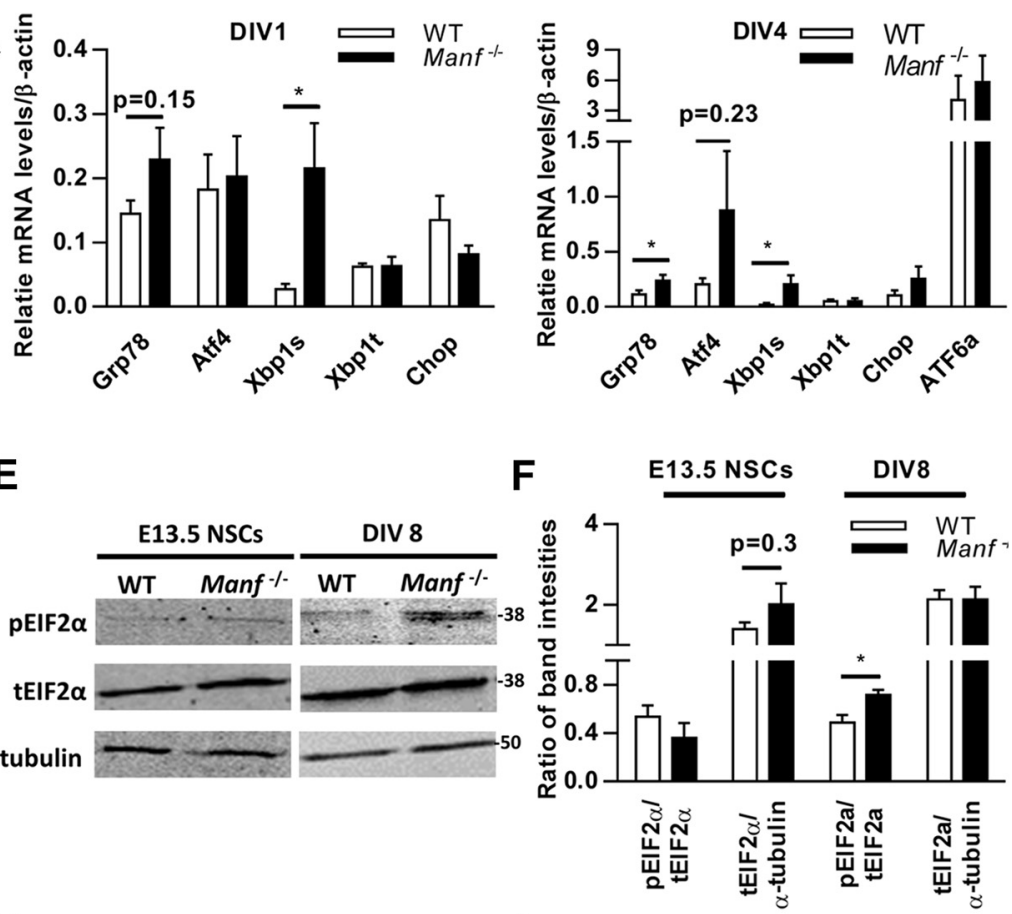

I

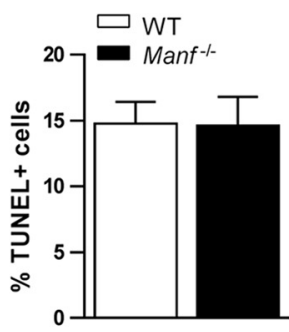

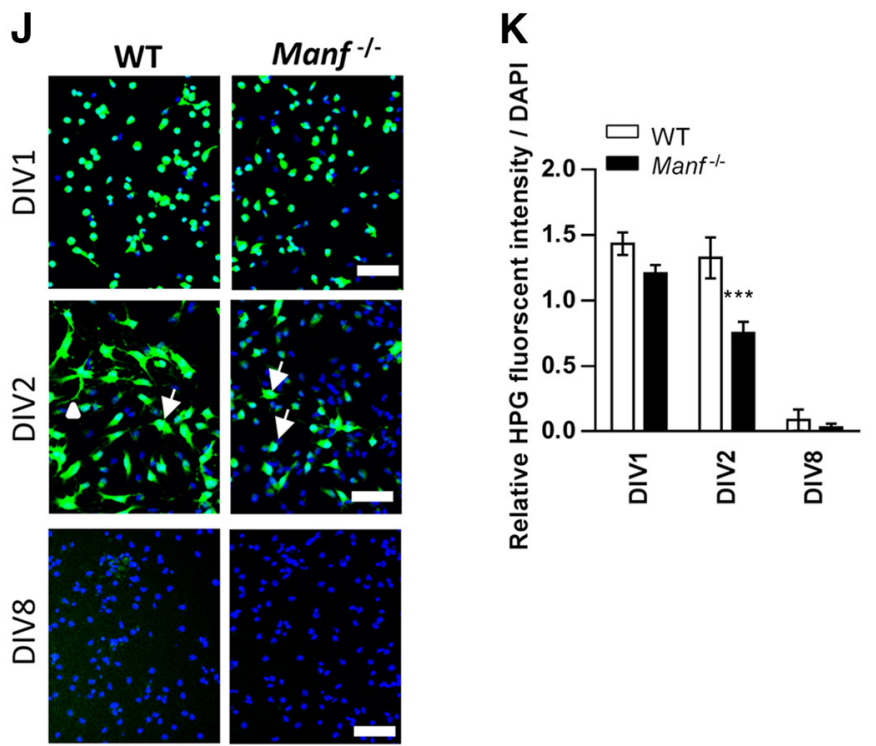

Figure 9. Unfolded protein-response genes are upregulated, and increased levels of p-elF2 $\alpha$ protein is found in the Manf ${ }^{-1-}$ NSCs during differentiation. $\boldsymbol{A}-\boldsymbol{D}$, qPCR analysis of UPR genes Atf4, Grp78, Chop, Xbp1s, Xbp1t in WT and Manf ${ }^{-/}$NSCs (A), and differentiated cells at DIV1 (B), DIV4 (C), and DIV $8(\boldsymbol{D}), n=8-11, * p<0.05, * * p<0.01$, Student's $t$ test. $\boldsymbol{E}$, Western blotting from NSCs and differentiated cells at DIV8. $\boldsymbol{F}$, Quantified intensities of Western blotting bands of p-elF2 $\alpha$ was compared to total amount 


\section{continued}

of (t)elF2 $\alpha$ and telF2 $\alpha$ to intensities of $\alpha$-tubulin, $n=4, * p<0.05$, Student's $t$ test. $\mathbf{G}$, TUNEL infrared fluorescence intensities were similar from cultures obtained from $\mathrm{Manf}^{-/-}$and WT differentiated cells at DIV4 and DIV8. $\boldsymbol{H}$, Representative photomicrographs of differentiated cells stained for TUNEL (green), DCX (red), and nuclei were counterstained with DAPI (blue); scale bar: $50 \mu \mathrm{M}$. I, Differentiated NSCs at DIV8 death assessed by TUNEL staining. J, WT and Manf ${ }^{-/-}$NSCs at DIV1, DIV2, and DIV8 incubated in HPG. Diagonal arrows denote the cytoplasmic localization of synthesized proteins and arrowhead indicates newly synthesized proteins spread to growing neurites. $K$, Quantified ratio of Click-iT HPG fluorescence to DAPI fluorescence intensities in WT and Manf ${ }^{-/-}$cells, two-way ANOVA, $p<0.01$, Bonferroni's post hoc test, $* * * p<0.001$.

levels were not altered during $\mathrm{Manf}^{-{ }^{--}}$neuronal differentiation.

Next, by using TUNEL staining In-Cell Westerns assay and immunofluorescent analysis we compared the apoptotic rate of differentiated cells between WT and Manf-/group. With In-Cell Westerns assay, we observed similar levels of TUNEL infrared fluorescent intensity in WT and Manf $^{-/-}$NSCs at DIV4 or DIV8 (Fig. 9G). Consequently, quantification of TUNEL + cells revealed equal levels of apoptotic cells in WT and Manf ${ }^{-/-}$NSCs at DIV8 (Fig. 9H,I). Thus, we suggest that loss of MANF results in increased UPR activation, which does not lead to cell death but rather might underlie the defects in neuronal differentiation seen in Manf ${ }^{-/-}$NSCs.

\section{Loss of MANF decreases de novo protein synthesis at the beginning of NSC differentiation}

The experiments described above indicate that loss of MANF increases ER stress and UPR signaling, and thus disturbs ER homeostasis during neuronal differentiation. Since activation of PERK and IRE-1 pathway directly regulate proteins synthesis, we wanted to study whether MANF deficiency further disturbs protein synthesis or processing when NSCs differentiate. We implemented a HPG-based assay for the detection of nascent protein synthesis. At DIV1, most WT and Manf ${ }^{--}$NSCs showed strong HPG-derived signals (Fig. 9J). After differentiation, at DIV2, most WT cells showed intense fluorescence in the cell soma and neurites (Fig. 9J). These signals are likely to reflect the presence of newly synthesized proteins localized in the neuronal soma (arrows) and disseminated to growing neurites (arrowhead). However, Manf ${ }^{-/}$cells had less HPG-derived signal compared to WT. Also, the signals in $\mathrm{Manf}^{-/-}$cells were limited to soma, which could explain the neurite sprouting defects in $\mathrm{Manf}^{-/-}$cells have not yet developed neurite sprouting. Quantification of the signal intensities revealed significantly lower intensity in differentiating Manf $^{-/-}$NSCs (DIV2; Fig. 9K). These results suggest that MANF deficiency results in a reduction of newly synthesized proteins at the beginning of cell differentiation. When we analyzed the newly synthesized proteins at DIV8, the very weak fluorescence signal was found both in WT and $\mathrm{Manf}^{-/}$cells (Fig. 9K), indicating that after differentiation there are less newly synthesized proteins needed.

\section{Discussion}

Previous studies have shown that exogenously added MANF has neuroprotective and neurorestorative properties (Airavaara et al., 2009; Voutilainen et al., 2009; Yang et al., 2014; Neves et al., 2016), and in vitro ER localization is needed for neuroprotection (Hellman et al., 2011; Mätlik et al., 2015). In our study using MANF antibody validated on MANF knockout tissues, we found that MANF is not only expressed in mature postmitotic neurons but that it is also expressed at high levels in the mitotic NSCs. We demonstrate for the first time that MANF is highly expressed in the neurogenic areas in the mammalian brain. Therefore, we focused on studying its role in NSCs in vitro and in vivo using MANF-deficient neurosphere cultures and developing mouse cortex, respectively.

By isolating NSCs from Manf ${ }^{--}$embryos, we discovered that when cultured in vitro, MANF-deficient NSCs have impaired neurite growth, and this was further verified in developing mammalian cortex in vivo. These findings raise the question of why the loss of MANF influences neurite growth but does not compromise cell proliferation or cell survival. Recent studies have indicated that MANF is an ER luminal protein, and interacts with the chaperone GRP78, and is secreted in response to ER stress in vitro (Mizobuchi et al., 2007; Apostolou et al., 2008; Glembotski et al., 2012; Mätlik et al., 2015; Lindahl et al., 2017). Three branches of UPR that are initiated by distinct ER stress transducers located on the ER membrane: PERK, IRE1, and activating transcription factor 6 (ATF6). Under basal conditions, these proteins are bound by the ER chaperone Grp78 (also known as Bip) and maintained in an inactive state (Bertolotti et al., 2000). When ER stress develops, GRP78 is sequestered by the misfolded polypeptides and, consequently, released from the three sensor proteins, which triggers activation of the UPR branches (Hetz, 2012). UPR restores protein homeostasis by suppressing protein translation, inducing ER-related molecular chaperones to promote refolding of unfolded proteins, removing unfolded proteins by activating the ER-associated protein degradation system and promoting cell survival. If the UPR fails to restore protein homeostasis in the cell, prolonged and unmitigated ER stress leads to CHOP-mediated cell death. During neural differentiation, dendrites acquire their morphology by branch sprouting, which is accompanied by an increased need for protein synthesis (Ramírez and Couve, 2011). Increased protein synthesis can trigger UPR, a homeostatic signaling pathway to cope with the increased demand for protein folding (Torre and Steward, 1996; Ju et al., 2004; Murakami et al., 2007; Ramírez and Couve, 2011). However, prolonged ER stress when UPR fails to restore the normal function of the ER causes aberrant neuronal differentiation, retardation in neurite outgrowth, or even cell death (Kitao et al., 2004; Galehdar et al., 2010; Lin et al., 2012; Zhao et al., 2013; Kawada et al., 2014). While the 
downstream targets of the UPR pathway are not well studied in differentiating neurons, increased elF2 $\alpha$ phosphorylation is known to lead to a global decrease in mRNA translation initiation and ATF4 upregulation, which disrupts cAMP-induced responses and interferes with neuronal differentiation (Roffé et al., 2013). In vitro, rhMANF treatment could restore neurite outgrowth at the beginning of differentiation, although it did not improve neurite extension in Manf $^{-/-}$cells at later time points. It should be noted that rhMANF was administered only once, and multiple administrations could have caused a more robust restorative effect. Since in postmitotic neurons MANF in vitro has not been shown to bind to cell surface receptors or protect cells (Hellman et al., 2011), our results suggest that MANF has different effects on undifferentiated cells. Whether the effect is mediated by MANF functioning specifically in the ER remains unknown. Nevertheless, this finding implies that extracellular MANF modulates the UPR to rescue neurite growth partially when mutant cells start to differentiate. Moreover, following increased need for protein synthesis and processing, Manf $^{-/-}$cells seem to have difficulties in coping with the increased load of unfolded proteins, which further increases ER stress and subsequently impairs neuronal differentiation leading to shorter neurite extensions. The levels of CHOP and ATF6 did not increase significantly during neuronal differentiation and lack of increase can explain why the loss of MANF does not compromise cell survival. Considering that $\sim 30 \%$ of newly synthesized proteins are misfolded during differentiation (Schwarz et al., 2004), it is likely that lack of MANF, interfering with ER homeostasis, causes deficits in the protein processing, transport, and secretion needed for the morphologic changes during neurite growth.

Drosophila melanogaster embryos lacking both maternal and zygotic DmMANF show there are robust deficits in axonal arborization of dopamine neurons (Palgi et al., 2009). However, it is important to note that DmMANF is dominantly expressed in glial cells surrounding dopaminergic neurons, which suggests that the neuronal maturation-promoting factor in the fly originates from glial cells. In addition, knockdown of MANF expression with antisense splice-blocking morpholino oligonucleotides in Danio rerio revealed that MANF is necessary for the development of the dopaminergic neurons (Chen et al., 2012). Surprisingly, deletion of MANF in mice leads to a progressive postnatal reduction of pancreatic $\beta$-cells followed by insulin-deficient diabetes (Lindahl et al., 2014). Different from invertebrate species (Palgi et al., 2009), MANF protein in the mammalian brain is widely localized in neural lineage cells, suggesting that MANF has important functions in neuronal development. During neuronal differentiation, neurite growth is a crucial step and regulated by multiple signaling pathways. In the developing cortex, deletion of MANF disturbs neurite growth. However, there is no decrease in the number of neurons in the mutant cortex, which was observed in the in vitro experiments. This discrepancy may be the result of the distinctive environments between in vitro and in vivo. Disruption of the three-dimensional environment, cell-cell contacts as well as the extracellular environment are limitations in in vitro experiments (Gordon et al., 2013). Therefore, cultivated $\mathrm{Manf}^{-/-} \mathrm{NSCs}$, which endure with increasing ER stress in a non-physiologic environment have difficulties to differentiate into neurons whereas, in vivo, extracellular environment and cell-cell connections can support $\mathrm{Manf}^{-/-}$neural precursor cells during differentiation. Otherwise, our data are difficult to interpret regarding the recent finding of MANF modulating immune system (Neves et al., 2016). Taken together, our results demonstrate a role of MANF in regulating the neurite extensions during the development of cerebral cortex.

In the developing cortex, the migration of newborn cells is directed away from the VZ/SVZ and radial migration is the main mechanism that creates the layer structure of excitatory neurons in the neocortex. In this study, a Manf $^{-/-}$at E18.5 had at thinner CP layer likely because early- and late-born neurons had not yet arrived to their destined positions. Following neuron migration to their specific layers of the cortex, the deficit is partially recovered at postnatal stages. Additionally, based on our neuronal birth-dating analysis, Manf ${ }^{-/}$mouse cortical neurons did not exhibit an inverted (outside-in) laminar formation pattern. This difference in migratory defects suggests that the mechanism in $\mathrm{Manf}^{-/-}$mice is distinct from that seen in reeler and related mutant mice (Mimura et al., 2008). Another explanation is that truncated or reduced organization of radial glial cells is responsible for the perturbed neuronal migration (Noctor et al., 2004). However, in Manf $^{-/-}$mice, the radial glial scaffold, which is stained by Nestin, was not altered. Actually, we found that loss of MANF causes shorter neurite extensions and lower levels of NF200. It has been shown that when neural precursor cells start to leave from the VZ/SVZ, they develop leading and trailing processes to exert cell migration (Hirai et al., 2006). Also, axon-like processes would continue to grow during radial migration of neocortical pyramidal neurons (Hatanaka and Murakami, 2002). Several studies have demonstrated that developing axons undergo sequential neurofilament-mediated stabilization in a proximal-distal manner, which supports continued axonal outgrowth (Lariviere and Julien, 2004; Yuan et al., 2012; Lee and Shea, 2014). Accordingly, neuronal migration and neurite growth are correlated and can depend on the same molecular mechanisms (Yamasaki et al., 2011). Given the importance of MANF in neurite growth, it is not surprising that MANF plays a significant role in the regulation of neuronal migration.

Nonetheless, loss of MANF, disturbing the process of neurite extensions and maturation, may also interfere with the time course of subtype generation of subcerebral projection neurons and lead to the compacted architecture with increased neuronal density at the postnatal stage. In mouse embryos, expression of CTIP2, a zinc finger transcription factor, is observed in young neurons as early as E11.5, when subcerebral neurons are generated (Leone et al., 2008). Then when deeper layer neurons acquire the specification of distinct subtypes, SP neurons, and Layer VI neurons (corticothalamic neurons) are characterized by high levels of Tbr1 expression, but low 
CTIP2 expression (Morimoto-Suzki et al., 2014). Otherwise, the Layer $V$ neurons are represented by the CTIP2 marker. At a later point in the embryogenic stage, when upper layer neurons are generated, Cux1 is mostly expressed in corticocortical projection neurons of Layer II-IV (Cubelos et al., 2010). Our results indicate that the subtype specification is disrupted in $\mathrm{Manf}^{-/}$mice, but the reason for this remains unknown. Further studies will need be done to investigate whether MANF affects transcription factors regulating the production of neuronal subtypes in a spatiotemporal manner (Alcamo et al., 2008; Chen et al., 2008; Bedogni et al., 2010), whether MANF directly controls the generation of Layer V or VI neurons as well as their distribution during development.

We have previously shown that $\mathrm{Manf}^{-/-}$mice suffer from a severe growth defect (Lindahl et al., 2014). However, with respect to brain and body weight ratio, we found no differences in the brain/body weight (\%) between genotypes at P56 (males: WT $1.9 \pm 0.0, n=4 ;$ Manf $^{-/-} 2.4 \pm$ $0.2, n=4$ and females: WT $2.5 \pm 0.1, n=7 ;$ Manf $^{-/-} 2.8 \pm$ $0.2, n=7$ ). Notably, conventional MANF-KO adult mice develop diabetes (Lindahl et al., 2014). At P28 serum insulin levels are already greatly decreased in mutant mice. Despite no change in random fed blood glucose levels in Manf $^{-1-}$ mice at P14, decreased glucose tolerance was found (Lindahl et al., 2014). As high blood glucose levels are implicated in affecting the development of different parts of the brain (Tayman et al., 2014), we used brains from embryonic and early postnatal Manf $^{-/-}$ mice to investigate the time-dependent differences in the cortical layer thickness. Thus, the thinner cortical layers in mutant embryos and pups are attributed to delayed neuronal migration and aberrant neuronal density. Brainspecific Nestin-Cre $\pm:: M a n f^{\mathrm{fl} / \mathrm{fl}}$ mice are viable and do not show any gross defects (Lindahl et al., 2014; Pakarinen and Lindahl, unpublished results). However, as MANF is still expressed in some cells in the brain of conditional Nestin-Cre $\pm::$ Manf ${ }^{f / / f l}$ brains (Pakarinen and Lindahl, unpublished results), we did not find this model suitable for our study.

Our study shows that MANF is not only expressed in postmitotic neurons but also in mitotic NSCs in the mammalian brain. We demonstrate that MANF does not affect self-renewal capacity or proliferation of NSCs and suggest that MANF is dispensable for neurogenesis. However, MANF plays a significant role in neurite growth in the process of neuronal differentiation and this, in turn, is likely the cause for delayed neuronal migration. This study is the first to demonstrate that MANF regulates neuronal extension in mammalian neurons and there is decreased in de novo protein synthesis and chronic ER stress on differentiation. In conclusion, these results suggest that MANF has a fundamental role in ER homeostasis during neurite growth and neuronal migration.

\section{References}

Airavaara M, Shen H, Kuo CC, Peränen J, Saarma M, Hoffer B, Wang $Y$ (2009) Mesencephalic astrocyte-derived neurotrophic factor reduces ischemic brain injury and promotes behavioral recovery in rats. J Comp Neur 515:116-124. CrossRef Medline
Airavaara M, Chiocco MJ, Howard DB, Zuchowski KL, Peränen J, Liu C, Fang S, Hoffer BJ, Wang Y, Harvey BK (2010) Widespread cortical expression of MANF by AAV serotype 7: localization and protection against ischemic brain injury. Exp Neurol 225:104-113. CrossRef Medline

Airavaara M, Harvey BK, Voutilainen MH, Shen H, Chou J, Lindholm P, Lindahl M, Tuominen RK, Saarma M, Hoffer B, Wang Y (2012) CDNF protects the nigrostriatal dopamine system and promotes recovery after MPTP treatment in mice. Cell Transplant 21:12131223. CrossRef Medline

Alcamo EA, Chirivella L, Dautzenberg M, Dobreva G, Fariñas I, Grosschedl R, McConnell SK (2008) Satb2 regulates callosal projection neuron identity in the developing cerebral cortex. Neuron 57:364-377. CrossRef Medline

Apostolou A, Shen Y, Liang Y, Luo J, Fang S (2008) Armet, a UPR-upregulated protein, inhibits cell proliferation and ER stressinduced cell death. Exp Cell Res 314:2454-2467. CrossRef Medline

Bedogni F, Hodge RD, Elsen GE, Nelson BR, Daza RA, Beyer RP, Bammler TK, Rubenstein JL, Hevner RF (2010) Tbr1 regulates regional and laminar identity of postmitotic neurons in developing neocortex. Proc Natl Acad Sci USA 107:13129-13134. CrossRef Medline

Bertolotti A, Zhang Y, Hendershot LM, Harding HP, Ron D (2000) Dynamic interaction of BiP and ER stress transducers in the unfolded-protein response. Nat Cell Biol 2:326-332. CrossRef Medline

Canty AJ, Dietze J, Harvey M, Enomoto H, Milbrandt J, Ibáñez CF (2009) Regionalized loss of parvalbumin interneurons in the cerebral cortex of mice with deficits in GFRalpha1 signaling. J Neurosci 29:10695-10705. CrossRef Medline

Chen B, Wang SS, Hattox AM, Rayburn H, Nelson SB, McConnell SK (2008) The Fezf2-Ctip2 genetic pathway regulates the fate choice of subcortical projection neurons in the developing cerebral cortex. Proc Natl Acad Sci USA 105:11382-11387. CrossRef Medline

Chen YC, Sundvik M, Rozov S, Priyadarshini M, Panula P (2012) MANF regulates dopaminergic neuron development in larval zebrafish. Dev Biol 370:237-249. CrossRef Medline

Cubelos B, Sebastián-Serrano A, Kim S, Moreno-Ortiz C, Redondo JM, Walsh CA, Nieto M (2008) Cux-2 controls the proliferation of neuronal intermediate precursors of the cortical subventricular zone. Cereb Cortex 18:1758-1770. CrossRef Medline

Cubelos B, Sebastián-Serrano A, Beccari L, Calcagnotto ME, Cisneros E, Kim S, Dopazo A, Alvarez-Dolado M, Redondo JM, Bovolenta P, Walsh CA, Nieto M (2010) Cux1 and Cux2 regulate dendritic branching, spine morphology, and synapses of the upper layer neurons of the cortex. Neuron 66:523-535. CrossRef Medline

Ferri RT, Levitt P (1995) Regulation of regional differences in the differentiation of cerebral cortical neurons by EGF family-matrix interactions. Development 121:1151-1160. Medline

Fukumitsu H, Ohtsuka M, Murai R, Nakamura H, Itoh K, Furukawa S (2006) Brain-derived neurotrophic factor participates in determination of neuronal laminar fate in the developing mouse cerebral cortex. J Neurosci 26:13218-13230. CrossRef Medline

Galehdar Z, Swan P, Fuerth B, Callaghan SM, Park DS, Cregan SP (2010) Neuronal apoptosis induced by endoplasmic reticulum stress is regulated by ATF4-CHOP-mediated induction of the $\mathrm{Bcl}-2$ homology 3-only member PUMA. J Neurosci 30:1693816948. CrossRef

Glembotski CC, Thuerauf DJ, Huang C, Vekich JA, Gottlieb RA, Doroudgar S (2012) Mesencephalic astrocyte-derived neurotrophic factor protects the heart from ischemic damage and is selectively secreted upon sarco/endoplasmic reticulum calcium depletion. J Biol Chem 287:25893-25904. CrossRef Medline

Godin JD, Creppe C, Laguesse S, Nguyen L (2016) Emerging roles for the unfolded protein response in the developing nervous system. Trends Neurosci 39:394-404. CrossRef Medline

Gordon J, Amini S, White MK (2013) General overview of neuronal cell culture. Methods Mol Biol 1078:1-8. CrossRef Medline 
Greig LC, Woodworth MB, Galazo MJ, Padmanabhan H, Macklis JD (2013) Molecular logic of neocortical projection neuron specification, development and diversity. Nat Rev Neurosci 14:755-769. CrossRef

Grove EA, Fukuchi-Shimogori T (2003) Generating the cerebral cortical area map. Annu Rev Neurosci 26:355-380. CrossRef Medline

Hatanaka Y, Murakami F (2002) In vitro analysis of the origin, migratory behavior, and maturation of cortical pyramidal cells. J Comp Neur 454:1-14. CrossRef Medline

Hellman M, Arumäe U, Yu LY, Lindholm P, Peränen J, Saarma M, Permi P (2011) Mesencephalic astrocyte-derived neurotrophic factor (MANF) has a unique mechanism to rescue apoptotic neurons. J Biol Chem 286:2675-2680. CrossRef

Hetz C (2012) The unfolded protein response: controlling cell fate decisions under ER stress and beyond. Nat Rev Mol Cell Biol 13:89-102. CrossRef Medline

Hirai S, Cui DF, Miyata T, Ogawa M, Kiyonari H, Suda Y, Aizawa S, Banba Y, Ohno S (2006) The c-Jun N-terminal kinase activator dual leucine zipper kinase regulates axon growth and neuronal migration in the developing cerebral cortex. J Neurosci 26:1199212002. CrossRef Medline

Ju W, Morishita W, Tsui J, Gaietta G, Deerinck TJ, Adams SR, Garner CC, Tsien RY, Ellisman MH, Malenka RC (2004) Activitydependent regulation of dendritic synthesis and trafficking of AMPA receptors. Nat Neurosci 7:244-253. CrossRef Medline

Kawada K, lekumo T, Saito R, Kaneko M, Mimori S, Nomura Y, Okuma Y (2014) Aberrant neuronal differentiation and inhibition of dendrite outgrowth resulting from endoplasmic reticulum stress. J Neurosci Res 92:1122-1133. CrossRef Medline

Kerosuo L, Fox H, Perälä N, Ahlqvist K, Suomalainen A, Westermarck J, Sariola H, Wartiovaara K (2010) CIP2A increases selfrenewal and is linked to Myc in neural progenitor cells. Differentiation 80:68-77. CrossRef Medline

Kitao Y, Hashimoto K, Matsuyama T, Iso H, Tamatani T, Hori O, Stern DM, Kano M, Ozawa K, Ogawa S (2004) ORP150/HSP12A regulates Purkinje cell survival: a role for endoplasmic reticulum stress in cerebellar development. J Neurosci 24:1486-1496. CrossRef Medline

Lariviere RC, Julien JP (2004) Functions of intermediate filaments in neuronal development and disease. J Neurobiol 58:131-148. CrossRef Medline

Lee S, Shea TB (2014) The high molecular weight neurofilament subunit plays an essential role in axonal outgrowth and stabilization. Biol Open 3:974-981. CrossRef Medline

Leone DP, Srinivasan K, Chen B, Alcamo E, McConnell SK (2008) The determination of projection neuron identity in the developing cerebral cortex. Curr Opin Neurobiol 18:28-35.

Lin WC, Chuang YC, Chang YS, Lai MD, Teng YN, Su IJ, Wang CC, Lee KH, Hung JH (2012) Endoplasmic reticulum stress stimulates p53 expression through NF- $\kappa$ B activation. PLoS One 7:e39120. CrossRef Medline

Lindahl M, Danilova T, Palm E, Lindholm P, Võikar V, Hakonen E, Ustinov J, Andressoo JO, Harvey BK, Otonkoski T, Rossi J, Saarma M (2014) MANF is indispensable for the proliferation and survival of pancreatic $\beta$ cells. Cell Rep 7:366-375. CrossRef Medline

Lindahl M, Saarma M, Lindholm P (2017) Unconventional neurotrophic factors CDNF and MANF: structure, physiological functions and therapeutic potential. Neurobiol Dis 97:90-102. CrossRef Medline

Lindholm $\mathrm{P}$, Voutilainen $\mathrm{MH}$, Laurén J, Peränen J, Leppänen VM, Andressoo JO, Lindahl M, Janhunen S, Kalkkinen N, Timmusk T, Tuominen RK, Saarma M (2007) Novel neurotrophic factor CDNF protects and rescues midbrain dopamine neurons in vivo. Nature 448:73-77. CrossRef Medline

Lindholm P, Peränen J, Andressoo JO, Kalkkinen N, Kokaia Z, Lindvall O, Timmusk T, Saarma M (2008) MANF is widely expressed in mammalian tissues and differently regulated after ischemic and epileptic insults in rodent brain. Mol Cell Neurosci 39: 356-371. CrossRef Medline
Mätlik K, Yu LY, Eesmaa A, Hellman M, Lindholm P, Peränen J, Galli E, Anttila J, Saarma M, Permi P, Airavaara M, Arumäe U (2015) Role of two sequence motifs of mesencephalic astrocyte-derived neurotrophic factor in its survival-promoting activity. Cell Death Dis 6:e2032 CrossRef Medline

McAllister AK, Lo DC, Katz LC (1995) Neurotrophins regulate dendritic growth in developing visual cortex. Neuron 15:791-803. Medline

Mimura N, Yuasa S, Soma M, Jin H, Kimura K, Goto S, Koseki H, Aoe $T$ (2008) Altered quality control in the endoplasmic reticulum causes cortical dysplasia in knock-in mice expressing a mutant BiP. Mol Cell Biol 28:293-301. CrossRef Medline

Mizobuchi N, Hoseki J, Kubota H, Toyokuni S, Nozaki J, Naitoh M, Koizumi A, Nagata K (2007) ARMET is a soluble ER protein induced by the unfolded protein response via ERSE-II element. Cell Struct Funct 32:41-50. Medline

Molyneaux BJ, Arlotta P, Menezes JR, Macklis JD (2007) Neuronal subtype specification in the cerebral cortex. Nat Rev Neurosci 8:427-437. CrossRef Medline

Morimoto-Suzki N, Hirabayashi Y, Tyssowski K, Shinga J, Vidal M, Koseki H, Gotoh Y (2014) The polycomb component Ring1B regulates the timed termination of subcerebral projection neuron production during mouse neocortical development. Development 141:4343-4353

Murakami T, Hino SI, Saito A, Imaizumi K (2007) Endoplasmic reticulum stress response in dendrites of cultured primary neurons. Neuroscience 146:1-8. CrossRef Medline

Neves J, Zhu J, Sousa-Victor P, Konjikusic M, Riley R, Chew S, Qi Y, Jasper H, Lamba DA (2016) Immune modulation by MANF promotes tissue repair and regenerative success in the retina. Science 353:aaf3646. CrossRef Medline

Noctor SC, Martínez-Cerdeño V, Ivic L, Kriegstein AR (2004) Cortical neurons arise in symmetric and asymmetric division zones and migrate through specific phases. Nat Neurosci 7:136-144. CrossRef Medline

O'Leary DD, Sahara S (2008) Genetic regulation of arealization of the neocortex. Curr Opin Neurobiol 18:90-100.

Palgi M, Lindström R, Peränen J, Piepponen TP, Saarma M, Heino TI (2009) Evidence that DmMANF is an invertebrate neurotrophic factor supporting dopaminergic neurons. Proc Natl Acad Sci USA 106:2429-2434. CrossRef Medline

Petrova P, Raibekas A, Pevsner J, Vigo N, Anafi M, Moore MK, Peaire AE, Shridhar V, Smith DI, Kelly J, Durocher Y, Commissiong JW (2003) MANF: a new mesencephalic, astrocyte-derived neurotrophic factor with selectivity for dopaminergic neurons. J Mol Neurosci 20:173-188. Medline

Ramírez OA, Couve A (2011) The endoplasmic reticulum and protein trafficking in dendrites and axons. Trends Cell Biol 21:219-227. CrossRef Medline

Roffé M, Hajj GN, Azevedo HF, Alves VS, Castilho BA (2013) IMPACT is a developmentally regulated protein in neurons that opposes the eukaryotic initiation factor $2 \alpha$ kinase GCN2 in the modulation of neurite outgrowth. J Biol Chem 288:10860-10869. CrossRef Medline

Sato H, Fukutani Y, Yamamoto Y, Tatara E, Takemoto M, Shimamura $\mathrm{K}$, Yamamoto $\mathrm{N}$ (2012) Thalamus-derived molecules promote survival and dendritic growth of developing cortical neurons. J Neurosci 32:15388-15402. CrossRef Medline

Schwarz A, Burwinkel M, Riemer C, Schultz J, Baier M (2004) Unchanged scrapie pathology in brain tissue of tyrosine kinase Fyndeficient mice. Neurodegener Dis 1:266-268. CrossRef Medline

Tayman C, Yis U, Hirfanoglu I, Oztekin O, Goktas G, Bilgin BC (2014) Effects of hyperglycemia on the developing brain in newborns. Pediatr Neurol 51:239-245. CrossRef Medline

Torre ER, Steward O (1996) Protein synthesis within dendrites: glycosylation of newly synthesized proteins in dendrites of hippocampal neurons in culture. J Neurosci 16:5967-5978. Medline 
Voutilainen MH, Bäck S, Pörsti E, Toppinen L, Lindgren L, Lindholm P, Peränen J, Saarma M, Tuominen RK (2009) Mesencephalic astrocyte-derived neurotrophic factor is neurorestorative in rat model of Parkinson's disease. J Neurosci 29:9651-9659. CrossRef Medline

Wang H, Ke Z, Alimov A, Xu M, Frank JA, Fang S, Luo J (2014) Spatiotemporal expression of MANF in the developing rat brain. PLoS One 9:e90433. CrossRef Medline

Woodworth MB, Custo Greig L, Kriegstein AR, Macklis JD (2012) SnapShot: cortical development. Cell 151:918-918.e1. CrossRef Medline

Yamasaki T, Kawasaki H, Arakawa S, Shimizu K, Shimizu S, Reiner O, Okano H, Nishina S, Azuma N, Penninger JM, Katada T, Nishina H (2011) Stress-activated protein kinase MKK7 regulates axon elongation in the developing cerebral cortex. J Neurosci 31: 16872-16883. CrossRef Medline

Yang S, Huang S, Gaertig MA, Li XJ, Li S (2014) Age-dependent decrease in chaperone activity impairs MANF expression, leading to Purkinje cell degeneration in inducible SCA17 mice. Neuron 81:349-365. CrossRef Medline

Yuan A, Rao MV, Veeranna, Nixon RA (2012) Neurofilaments at a glance. J Cell Sci 125:3257-3263.

Zhao H, Liu Y, Cheng L, Liu B, Zhang W, Guo YJ, Nie L (2013) Mesencephalic astrocyte-derived neurotrophic factor inhibits oxygen-glucose deprivation-induced cell damage and inflammation by suppressing endoplasmic reticulum stress in rat primary astrocytes. J Mol Neurosci 51:671-678. CrossRef Medline 